\title{
TRADE IN TECHNOLOGY: \\ A POTENTIAL SOLUTION TO THE \\ FOOD SECURITY CHALLENGES OF THE 21ST CENTURY
}

\author{
Thomas W. Hertel \\ Uris L.C. Baldos \\ Keith O. Fuglie \\ Working Paper 27148 \\ http://www.nber.org/papers/w27148
NATIONAL BUREAU OF ECONOMIC RESEARCH
1050 Massachusetts Avenue
Cambridge, MA 02138

May 2020

Presented to the NBER Workshop on Agricultural Trade, May 1, 2020. Revised and extended version of a paper first presented at the "New Malthusianism Conference" held at Cambridge University, December 12-13, 2018. The views expressed herein are those of the authors and do not necessarily reflect the views of the National Bureau of Economic Research, the U.S. Department of Agriculture or the Economic Research Service

At least one co-author has disclosed a financial relationship of potential relevance for this research. Further information is available online at http://www.nber.org/papers/w27148.ack

NBER working papers are circulated for discussion and comment purposes. They have not been peer-reviewed or been subject to the review by the NBER Board of Directors that accompanies official NBER publications.

(C) 2020 by Thomas W. Hertel, Uris L.C. Baldos, and Keith O. Fuglie. All rights reserved. Short sections of text, not to exceed two paragraphs, may be quoted without explicit permission provided that full credit, including $(\odot$ notice, is given to the source. 
Trade in Technology: A Potential Solution to the Food Security Challenges of the 21st Century Thomas W. Hertel, Uris L.C. Baldos, and Keith O. Fuglie

NBER Working Paper No. 27148

May 2020

JEL No. Q16,Q17,Q56

\begin{abstract}
$\underline{\text { ABSTRACT }}$
The recent rise in caloric undernutrition in Sub-Saharan Africa (SSA) demonstrates the continued relevance of the Malthusian footrace between food availability and population. Sluggish growth in farm productivity in SSA has brought to the fore the key role of agricultural technology in alleviating future food insecurity. We develop a model of technology, food security and international trade with three distinct channels for technology reduce food insecurity in SSA. The first is via greater domestic R\&D investment. An alternative is to import technologies from other countries with significant knowledge capital. The third role for technology to resolve the Malthusian dilemma in SSA is that of 'virtual technology trade', i.e., importing technological investments undertaken elsewhere through cheaper imported food. To assess the relative contribution of each channel to food security in Africa, we employ a partial equilibrium, quantitative trade model, augmented by a temporal relationship between R\&D investments, knowledge capital and agricultural productivity. Over the historical period: 1991-2011 we find that direct R\&D investments in SSA have been the dominant vehicle for lowering food prices in Africa. Looking forward to 2050, we find that virtual technology trade will be the most important vehicle for reducing non-farm undernutrition in Africa.
\end{abstract}

Thomas W. Hertel

Department of Agricultural Economics

Purdue University

1145 Krannert Bldg. West

Lafayette, IN 47907

hertel@purdue.edu

Uris L.C. Baldos

Purdue University

403 W. State St.

West Lafayette, IN 47907

ubaldos@purdue.edu
Keith O. Fuglie

Department of Agriculture

keith.fuglie@usda.gov 


\section{Background and Motivation}

With the path of $20^{\text {th }}$ century food prices now comfortably in the rearview mirror (Figure 1), the question of whether agricultural technological progress would be able to keep pace with growing population appears to have been put to rest. The global agricultural price index in the year 2000 was only one-quarter of its value in 1900, and just $40 \%$ of its average value at the end of the 1970 s. This is clear evidence that, over the broad sweep of the $20^{\text {th }}$ century, improvements in agricultural technology led to strong output growth, outpacing population growth (Figure 1). Of course, there were many commodity price spikes that arose during this time, with the most dramatic coming in the wake of the Russian crop failure during the early 1970s when this price index more than doubled. A later doubling occurred at the beginning of the $21^{\text {st }}$ century, when a perfect storm of growing bioenergy demands, low commodity stocks and crop failures led to the index rising from less than 40 to more than 80 over a decade’s time (Abbott, Hurt, and Tyner 2011). As with the earlier price spikes, this led to a flurry of concern about Malthusian scarcity scenarios, and a burst of investments in agricultural research and development (R\&D). However, as with the earlier price booms, all indications are that this one is also on the wane (Figure 1), aided by the slowing rate of growth in global population (Baldos and Hertel 2016).

While the outcome of the global footrace between food supply and demand seems no longer in doubt, this is not the case within particular regions - most notably Sub Saharan Africa (SSA), where virtually all of the world's net population growth between today and the end of this century is expected to arise (UN Population Division 2015). Indeed, the reluctant decline in fertility in this region has caused the United Nations Population Division to revise upward its global population forecasts. Niger is the poster child for this challenge, with a fertility rate of 7.5 children per woman - a figure which has been found to be below the desired rate of fertility in that country (INS/Niger and International 2013). If productivity growth in agriculture was also 
proceeding at a record-breaking pace, this demographic anomaly would be of lesser concern. However, lack of investment in national agricultural research, poor dissemination of new technologies, weak institutions and civil unrest have resulted in below average rates of agricultural productivity growth in the region (Fuglie and Rada 2013). It is this combination of high population growth and low productivity growth that has allowed the Malthusian challenge to re-enter the debate in SSA. Indeed, since 2011, rates of undernutrition in this region have begun to rise, after more than a decade of steady decline (FAO et al. 2019).

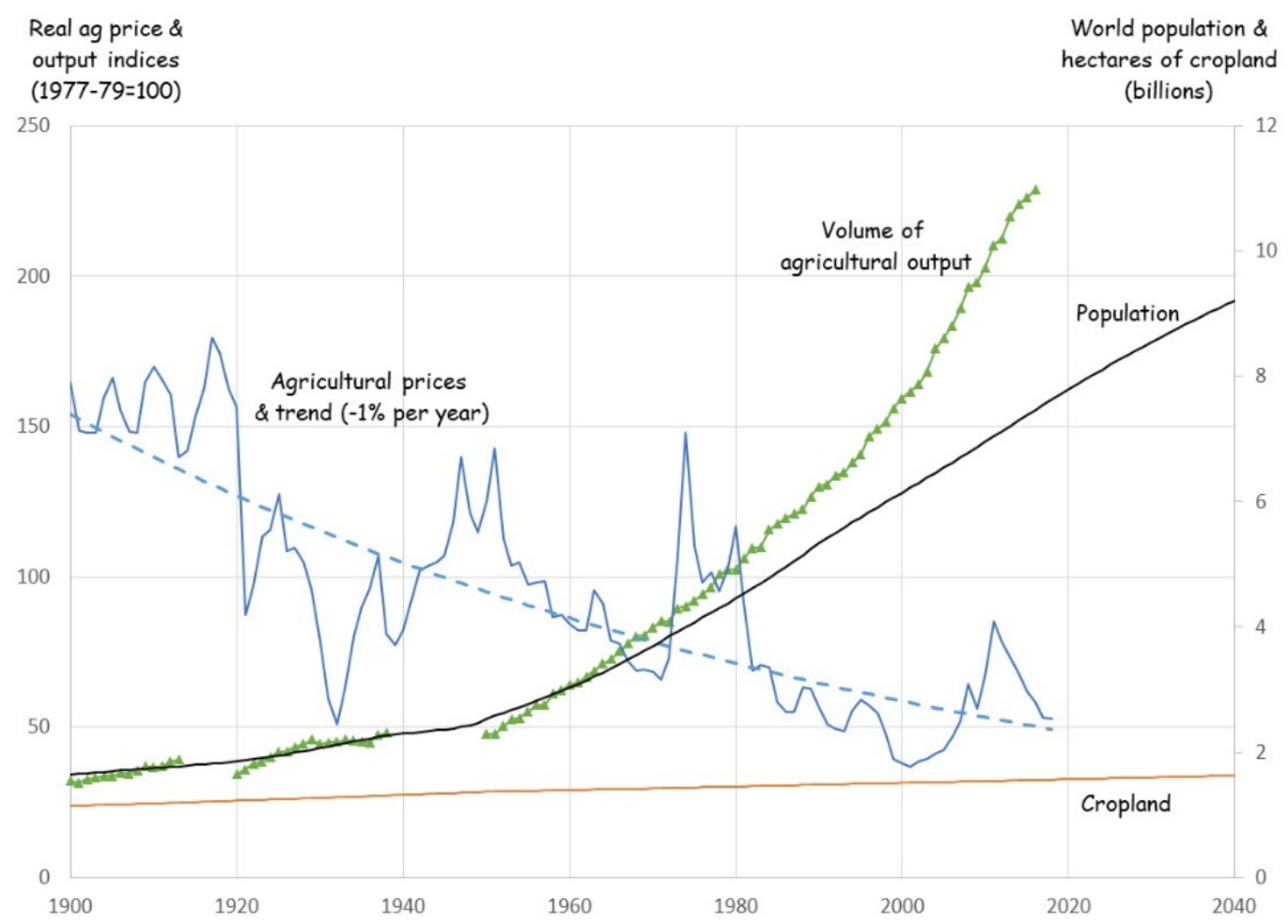

Figure 1. Evolution of global population, cropland, and real agricultural output and price indices since 1900. Source: Fuglie et al. (2019). The real agricultural price index is the Grilli-Yang price index of traded agricultural commodities divided by the US GDP price index.

Absent a dramatic shift on the demographic front, we must look to the technology side of this regional footrace for a solution. Greater investment in national agricultural research institutions in Africa is clearly an important part of picture. However, given the extremely long lag between public R\&D investment in agriculture and improved productivity growth - historically 
in the United States it has taken two decades for R\&D spending to achieve peak impact (Baldos et al. 2019) - such investments will likely not solve the near-term challenge. This brings us to the topic of trade - more specifically: trade in agricultural technology. In this paper we will distinguish between two types of trade in technology. The first, dubbed direct trade in technology, focuses on the transfer of knowledge from overseas. Historically, direct transfer of agricultural technology has been hampered by the challenges of adapting solutions from one agro-ecosystem and economic environment to another. Technologies developed for irrigated Asian agriculture have generally proven ineffective in SSA (Pingali 2012), and the empirical evidence shows little in the way of ‘technology spill-ins’ from rich countries in temperate regions to tropical zones (Fuglie 2018; Hayami and Ruttan 1985). However, R\&D in the emerging economies may prove more transferable to SSA given their closer environmental proximity. We focus on this type of technology spill-in as we consider the potential for direct trade in technology.

We have named the second type of trade in technology 'virtual technology trade' as it is fully in the spirit of the growing literature on virtual water trade (Allan 1998; Yang and Zehnder 2007). This literature points out that water-intensive crops can be imported in lieu of growing them domestically - hence the idea that these countries are importing 'virtual water'. In the case of agricultural technology, we suggest that one piece of the solution to the Malthusian challenge in the SSA region is to import food from regions where technological improvements are outpacing population growth. (In section 3 below, we will develop a precise definition of what we mean by virtual technology trade.) Historically, virtual trade in technology has been limited by restrictive agricultural trade policies, motivated by self-sufficiency targets as well as concerns about food safety, genetically modified crops, and a host of other factors. Therefore, in the results section of 
this paper, we will show how the potential for virtual technology trade is critically dependent on the extent to which the SSA region becomes more integrated into global agricultural markets.

While a number of models have produced long-term projections of supply and demand balances in world agriculture (see von Lampe et al. 2014 for a summary and comparison of 10 of the more prominent ones), almost all have assumed exogenously determined rates of productivity growth. Only a few studies have attempted to model future productivity as a function of R\&D spending (Lobell, Baldos, and Hertel 2013; Nelson et al. 2010). These models assume a single parameter that indicates the efficiency with which R\&D investment produces technical change, i.e., the percentage change in agricultural productivity expected from a $1 \%$ change in $R \& D$ spending, and restrict this relationship to a particular country or geographic region. State-of-theart models of R\&D capital, however, take into account the substantial lag between R\&D spending and changes in farm productivity. This lag is typically one or two decades, beyond which these productivity effects wear off due to R\&D capital depreciation (Alston et al. 2010; Baldos et al. 2019). Only Nelson et al. (2010) allowed for eventual R\&D capital depreciation, and none of these studies have taken into account how the pattern of past R\&D spending may affect future productivity. Clearly, with long R\&D lags, countries like China that have increased R\&D spending rapidly in recent years will likely have a different productivity trajectory than countries with more stable R\&D spending, such as the United States.

The present paper extends prior work by (i) projecting future growth in R\&D capital stocks, taking into account past R\&D spending patterns and allowing for R\&D capital depreciation, (ii) accounting for differences in the quality and capacity of national agricultural R\&D systems by allowing R\&D elasticities to vary across global regions, based on a review of more than 40 econometric studies of past performance (Fuglie 2018); and (iii) incorporating the potential for 
international R\&D spillovers - that productivity growth in one region depends not only on that region's R\&D spending but also on technology transfer from other parts of the world.

In the next section of the paper, we provide a brief review of the evidence on technological progress in agriculture, its role in driving growth in farm output, the determinants underlying these productivity improvements, and the evidence regarding international technology spillovers. We then introduce our theoretical framework and identify the roles of direct and virtual technology trade in overcoming the Malthusian challenges faced by many countries in Africa. This leads naturally into our quantitative trade model, which is a higher-dimensional version of the theoretical model, with geographic heterogeneity and explicit temporal linkages from R\&D spending and spillovers to regional productivity growth in agriculture. We use this framework first to decompose historical drivers of regional crop prices and then to investigate the potential for trade in technology to lower food prices and bolster food security in those countries currently experiencing the fastest rates of population growth in the world.

\section{Determinants of Agricultural Productivity}

Globally, raising agricultural output has come to rely on improving efficiency rather than on increasing the use of land, labor or industrial inputs. As the growth decomposition in Figure 2 shows, since the 1990s improvement in total factor productivity (TFP) has accounted for about three-quarters of the growth in world agricultural output (Fuglie 2015). ${ }^{1}$ The acceleration in agricultural TFP growth since the 1990s primarily occurred in developing countries and to a lesser

\footnotetext{
${ }^{1}$ Given data limitations, the growth decomposition in Figure 2 is only approximate. Output is the value of crop and livestock commodity production at 2005 global average farmgate prices, land includes area in crops and pasture, measured as hectares of 'rainfed-equivalent cropland', where irrigated areas and pasture are quality-adjusted, labor is number of persons working on farms, capital consists of stocks of farm machinery and animals, and intermediate inputs include inorganic fertilizers and animal feeds. The contribution of each input to output growth is the growth rate of that input multiplied by its cost share. TFP is the difference in growth between output and aggregate inputs. See Fuglie (2012) for a discussion of methods and limitations.
} 
extent in transition economies of the former Soviet bloc (where, prior to 1990, agricultural TFP growth had been negative). In highly industrialized countries, TFP was already the primary source of agricultural growth as early as the 1950s or 1960s. Worldwide, use of industrial inputs like inorganic fertilizers grew very rapidly in the 1960s and 1970s, and this growth continues today but at a much slower pace. Most of the growth in agricultural land has come through quality improvement (converting pastures into cropland or extending irrigation) rather than expanding farming to new lands. The growth rate of agricultural labor has slowed sharply since the 1980s, turning negative in the early years of the $21^{\text {st }}$ Century.

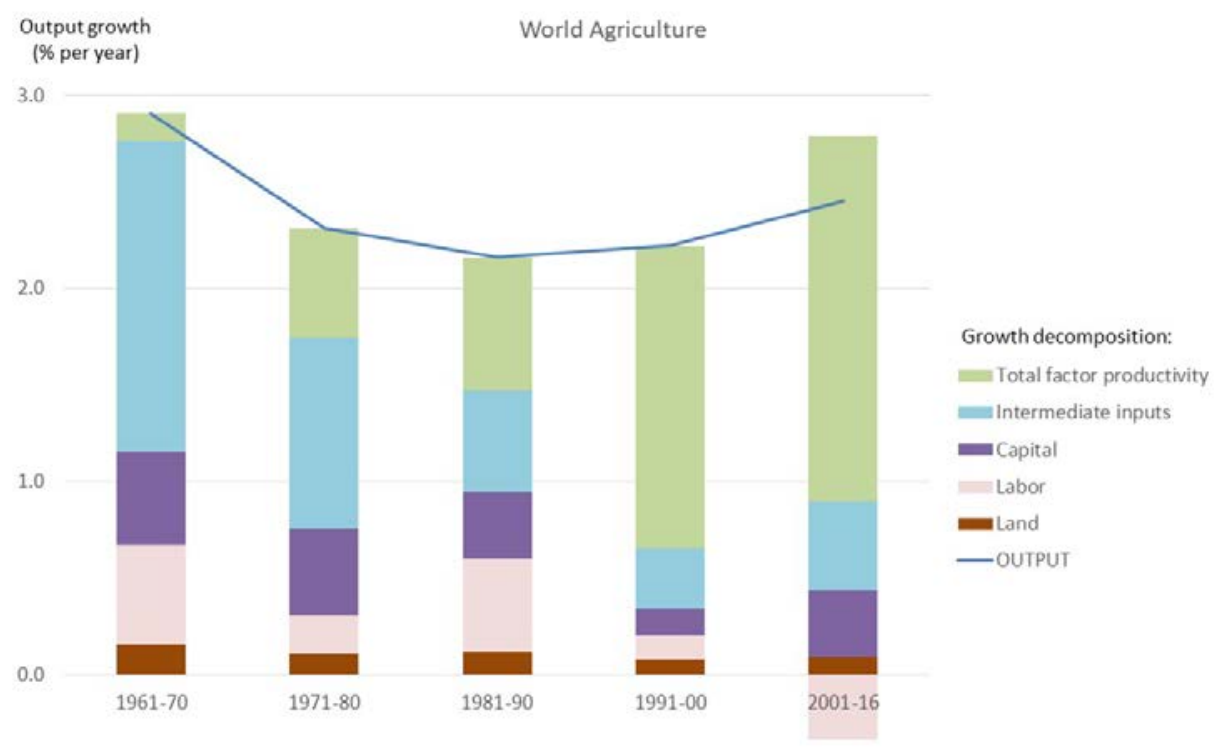

Figure 2. Sources of global agricultural growth, 1961-2016, showing the increasing importance of TFP. Source: USDA-ERS (2019).

The increasing importance of TFP to agricultural growth raises an important question. Is the improved efficiency in agriculture due primarily to reallocating resources (transferring excess labor out of agriculture, consolidating farms to achieve economies of scale, etc.), or to adoption of new technologies and practices that do a better job of converting resources - energy, water, and nutrients - into commodities? If it is the former, then encouraging reallocation of resources may 
stimulate further improvement in productivity, at least until such opportunities are exhausted. ${ }^{2}$ (In the theoretical model developed below we abstract from this driver of productivity.) If it is the latter (technological change), then prospects for sustaining growth require an adequate pipeline of new technologies under development. However, the extent to which investments in R\&D are needed in all countries or regions would seem to depend greatly on the prospects for trade in technology, either in its direct or virtual forms.

Empirical research on the drivers of past TFP growth in agriculture have found both resource reallocation and adoption of new technology to be important. Changes in relative factor prices, market liberalization, and institutional or policy reforms that incentivized improved use of resources have often provided a powerful, though short-term, boost to productivity. Boserup (1965) and Hayami and Ruttan (1985) documented the effect of changing factor scarcity in inducing improvements in agricultural productivity. Perhaps the most dramatic example of how institutional reform can stimulate productivity was the decollectivization of Chinese agriculture beginning in 1978. Productivity advanced quickly when farms were once again managed by individual households, who retained the benefits of their own efforts (Lin 1992). Fuglie and Rada (2013) also found positive though more modest productivity gains from structural adjustment reforms in SSA. But such gains from resource adjustment face diminishing returns, and growth may not be sustained after the initial response to new opportunities. Countries that have been able to keep agricultural TFP rising over the long-term have largely been those that have invested resources in agricultural $R \& D$ and encouraged the private sector to manufacture productivity enhancing industrial inputs for farms (Hayami and Ruttan 1985; Fuglie 2012).

\footnotetext{
${ }^{2}$ Institutional and cultural barriers constraining resource reallocation have often been cited as a cause of low productivity in developing countries (Caselli 2005; Adamopoulos et al. 2017) but some recent work has found that the extent of agricultural land and labor market distortions may be less than previously thought (Fuglie et al. 2019).
} 
Because environmental conditions (rainfall, temperature, humidity, soils, topography, etc.) have such an important influence on agriculture, direct spillover of agricultural technologies is likely to be limited across global geographies. Socio-economic and market factors also constrain spillovers. Farmers in isolated areas with limited access to urban or international markets, for example, are not likely to be able to achieve similar efficiency gains from scale and specialization as farmers with ready access to such markets.

Empirical studies on sources of agricultural TFP growth have found few cases of international R\&D spillovers between developed and developing countries, or between developing countries themselves, although spillovers have occurred between temperate-zone developed countries (Fuglie 2018). For example, using patent data, Johnson and Evenson (1999) show that most international technology transfer in agriculture occurs between high-income, temperate countries. Eberhardt and Teal (2013) find that agricultural TFP growth is strongly correlated across similar agro-climatic environments.

One factor that may be have constrained trade in agricultural technology within tropical zones is the limited capacity of national R\&D systems in these regions. Hayami and Ruttan (1985) characterized three stages of national capacities in agricultural research - the ability to first screen, then adapt and finally invent. Nascent R\&D systems are limited to testing or screening technologies developed elsewhere, while somewhat more advanced systems can adapt them to local conditions, such as crossing an imported crop variety with a local cultivar to get an improved variety adapted to local conditions. Most agricultural R\&D systems in developing countries are at this second stage, while a few, namely those in the large emerging economies of Brazil, China and India, are rapidly moving toward the inventive stage. At this third stage, they are capable of developing general purpose technologies that may have broad application elsewhere, especially in 
agro-climatic zones not too dissimilar from their own. The development of the tropical soybean by the Brazilian national agricultural research institute, EMBRAPA, and hybrid rice by the Chinese national research system, provide examples of the consequences of this inventive capacity. The emergence of greater R\&D capacity across the tropics raises the prospect of boosting productivity in the SSA region through new opportunities for direct trade in technology, a prospect we consider in our analysis below.

Another factor complicating growth trajectories in agriculture is the role of environmental policies. Engels Law suggests that, at the margin, non-agricultural demands for environmental resources like land, water and greenhouse gas emissions mitigation will grow in importance, relative to food, as societies become wealthier. This is already manifesting itself in many high income countries, where environmental restrictions and conservation measures are a significant part of agricultural policies. Reforms since the 1990s to the EU's Common Agricultural Policy (CAP), for example, have reduced price supports for agricultural commodities while at the same time increasing payments to farmers for retiring land from production and adopting other conservation measures. Several countries have also tightened regulations on nutrient loadings and chemical use by farms, and placed restrictions on the use of certain technologies, such as genetically modified (GM) crops and animal antibiotics and growth hormones (OECD 2011).

One result of EU agricultural policies has been to pull more resources out of agricultural production. According to statistics compiled by USDA/ERS (2019), between 1990 and 2016, the aggregate amount of land, labor, capital and intermediate inputs employed in northwest European agriculture declined by about one fourth. However, continued improvement in TFP kept farm output from following suit - it remained roughly constant in real terms over this period (Figure 3). In contrast, in the US and Canada, aggregate inputs remained almost constant over the 1990- 
2014 period and steady TFP growth led to rising agricultural output. Viewed through this lens, Europe used TFP growth to improve environmental outcomes rather than increase the supply of food, while North America chose to boost food output at the expense of potential ongoing environmental damages.
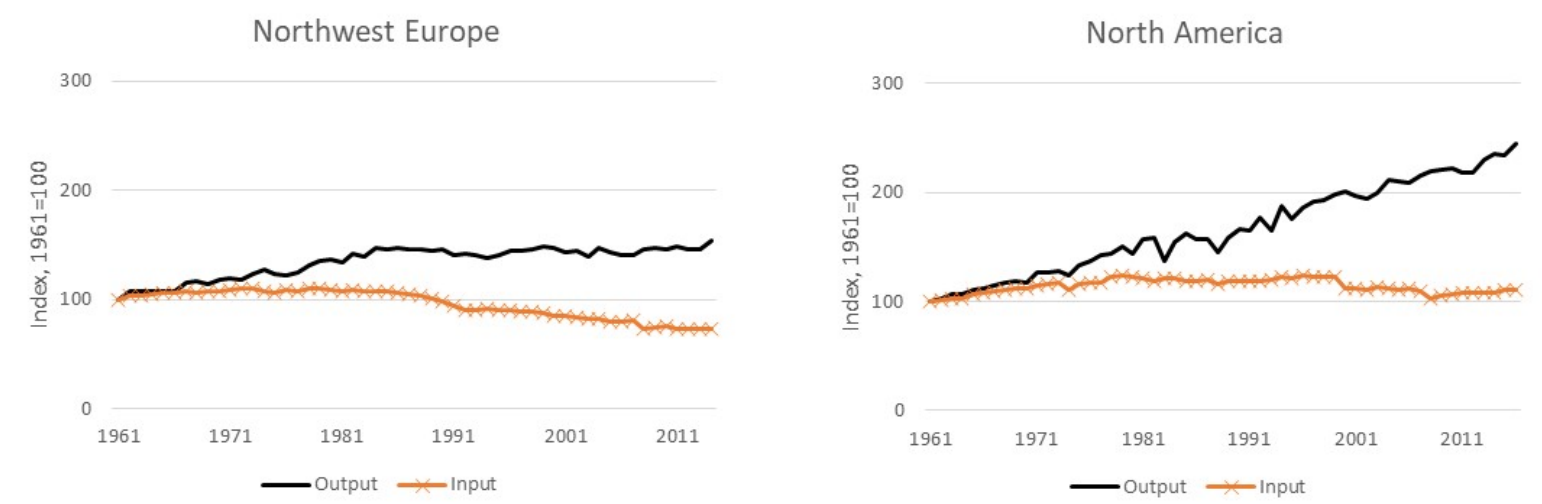

Figure 3. Indices of real agricultural output and aggregate input use in Northwest Europe and North America, 1961-2016. Source: USDA/ERS (2019).

In the context of a global trading equilibrium, differential rates of TFP growth among countries or regions can be expected to affect competitiveness and comparative advantage, leading some countries to expand their agricultural sector and others to contract. In our quantitative analysis below, we consider the possibility that some countries may impose environmental restrictions that constrain virtual trade in agricultural technology, and we explore how this might affect the Malthusian outcome in SSA.

\section{Theoretical Framework}

Our theoretical framework is designed to be as simple as possible while still addressing all of the key mechanisms determining the role of technology trade in resolving the food security dilemma in SSA. To introduce notation and key concepts, we begin by exploring the Malthusian footrace in the context of a single region, closed economy, thereupon moving to a two-region model to introduce our concepts of trade in technology. 


\subsection{Single Region Model}

Consider an aggregate, agricultural sector comprised of many farms subject to entry/exit based on profitability. Regardless of the farm level technology, free entry and exit in the context of cost minimization will lead to the aggregate industry operating in the neighborhood of constant returns to scale (Diewert 1981). In the spirit of simplicity, we group the determinants of food output into three distinct components: technology, the key factors constraining long run expansion (climate, land and water - dubbed 'land'), and non-land inputs (including labor, capital and purchased inputs). With just two inputs, the Constant Elasticity of Substitution (CES) production function is sufficiently flexible to locally approximate any technology, leading to the following relationship: $Q_{O}=A\left(\phi_{L} Q_{L}^{-\rho}+\phi_{N} Q_{N}^{-\rho}\right)^{-1 / \rho}$

If we further assume that the land input is supplied inelastically, with the non-land inputs in perfectly elastic supply from the non-farm economy over the long run, then the Malthusian challenge can be formulated in terms of the percentage change in food prices, which evolve according to the following relationship (for all derivations, see supplementary material):

$$
p_{O}=\left[\Delta_{D}-a\left(\varepsilon_{S}+1\right)\right] /\left[\varepsilon_{S}+\varepsilon_{D}\right]
$$

Where lower case variables denote percentage changes, i.e., $p_{O}=100 * d P_{O} / P_{O}$ is the growth in food prices and $a=100 * d A / A$ is the rate of TFP growth in agriculture. TFP growth stands in opposition to the percentage growth in food demand due to rising population (and income), $\Delta_{D}$. The sign and magnitude of the long run equilibrium price change depends on the elasticity of supply, $\varepsilon_{S}=\theta_{L}^{-1} v_{L}+\sigma\left(\theta_{L}^{-1}-1\right)$, along with the (assumed constant) price elasticity of demand for food, $\varepsilon_{D}$. The price elasticity of supply for agricultural products, depends, in turn, on the potential to expand area: $\theta_{L}^{-1} v_{L}$, where $\theta_{L}$ is the cost share of land and water in production, $v_{L}$ is the 
responsiveness of harvested area to land returns, and $\sigma\left(\theta_{L}^{-1}-1\right)$ is the potential for further intensification of production, which, in turn, depends on the cost share of land and elasticity of substitution between land and non-land inputs, $\sigma=1 /(1+\rho)$.

Equation (2) highlights the Malthusian footrace between growing demand and growth in agricultural productivity, where the latter is modulated by the responsiveness of supply to scarcity. If agricultural supplies are price-inelastic, $\varepsilon_{S}=0$, then the outcome of this footrace simply boils down to a question of whether TFP can grow at a faster rate than food demand. As noted in the introduction, the problem at present in the SSA region is that population growth remains stubbornly high, while agricultural TFP growth has historically been amongst the lowest in the world. This mismatch has resulted in food scarcity, rising prices, and rising undernutrition in many parts of SSA.

Fortunately for SSA, the empirical evidence suggests that there exists significant supply response to price in the agricultural sector, once transactions costs are taken into account (Magrini, Balié, and Morales-Opazo 2018). This means that, in addition to the impact of an outward supply shift due to TFP growth, the ensuing increase in profitability in the sector will further boost production by drawing additional land and non-land inputs into the sector. This point is highlighted in the solution for equilibrium agricultural output growth as a function of increasing demand as well as TFP growth:

$q_{O}=\left[a \varepsilon_{D}\left(\varepsilon_{S}+1\right)+\varepsilon_{S} \Delta_{D}\right] /\left[\varepsilon_{S}+\varepsilon_{D}\right]$

This supply response notwithstanding, it is critical to improve TFP growth rates in the region if one hopes to attract sufficient resources and boost output fast enough to keep prices from rising. Indeed, the food security goal in this region is to significantly reduce food prices - particularly during the 'lean season' - in order to reduce undernutrition in SSA. 
Within this framework, there are four obvious points of entry to overcome the Malthusian threat in the SSA region, encapsulated in equation (2). The first is to slow population growth $\left(\Delta_{D} \downarrow\right)$. This has been successful in some parts of the continent. For example, Ethiopia has reduced its population growth rate by a full percentage point since 1990 (Ethiopia Population 2019), but in the poorest countries in West Africa, there is significant resistance to discussion of family planning, let alone implementing a program targeting fertility rates (INS/Niger and International 2013). The next point of entry in equation (2) is to boost TFP growth $(a \uparrow)$. As discussed in the introduction, this has been the primary driver of agricultural output growth in the industrialized countries since the end of WWII (Hayami and Ruttan 1985; Fuglie 2015). However, it can take decades for public spending on agricultural R\&D to actually boost TFP growth. Indeed, Baldos et al. (2019) estimate that the productivity impacts of public R\&D spending in the United States peaked 22 years after the initial investment. And its impact persists for nearly 50 years! With half of its population under 15 years of age and entering the child-bearing stage of their lifetime, countries like Niger (INS/Niger and International 2013) cannot wait that long for improvements in agricultural TFP.

This brings us to the idea of trade in technology - the vehicle for delivering the last two options for resolving the Malthusian dilemma in SSA. As noted above, the first, and most obvious, type of technology trade involves importing existing technologies from other regions. This is typically termed 'technology spillover' and this idea inspired many foreign aid projects in the 1950's - introducing new breeds of livestock and new seed varieties into Africa, among other efforts. Unfortunately, most of these projects failed miserably with the livestock falling prey to local disease and lack of management infrastructure and the new seed varieties failing due to insufficient nutrients, irregular precipitation and vulnerability to local pests. This poor track record 
is evident in the empirical work that finds only very limited evidence of direct agricultural technology transfers from OECD countries into the tropical regions of Africa (Johnson and Evenson 1999; Eberhardt and Teale 2013; Fuglie 2018). However, with growing capacity for research discovery in emerging economies like Brazil, China, and India, that share more agroecological and socio-economic characteristics with Africa, the potential for R\&D spillovers increases. We explore below the potential for such 'direct technology trade' to solve the Malthusian challenge in Africa.

As noted above, we dub the second type of technology trade, as 'virtual trade in technology' - drawing inspiration from the literature on 'virtual water trade' (Allan 1998; Yang and Zehnder 2007). In this case, rather than importing the technology itself, we explore the role of international commodity trade in allowing agricultural products produced elsewhere with new technologies to resolve the upward price pressures resulting from rapid population growth in the face of sluggish TFP growth in SSA agriculture. In order to render this idea more concrete, we expand the model introduced above to two regions and consider the impact of TFP growth in the rest of the world (RoW) on food prices, production and imports in SSA. Specifically, we evaluate the percentage change in SSA net imports, relative to worldwide production, as a function of technological innovation in the rest of the world. To address this issue, we turn now to the two region model.

\subsection{Two Region Model}

We begin with the following expression for the change in net imports into SSA:

$$
t=100 * d M^{S S A} / Q^{W}=\beta q o_{D}^{S S A}-\alpha q o_{S}^{S S A}
$$

where $M=Q_{D}^{S S A}-Q_{O}^{S S A}$ reflects net imports into the SSA region, $T=M / Q^{W}$ expresses these net imports as a portion of global supply, $\alpha=Q_{O}^{S S A} / Q^{W}$ is SSA's share of global supply (which equals 
global demand by virtual of global market clearing), and $\beta=Q_{D}^{S S A} / Q^{W}$ is SSA's share of global demand (which equals supply in this equilibrium model). Solving for percentage change in the global price, we have:

$p_{O}=-\left(\varepsilon_{S}^{R o W}+1\right) a^{R o W} /\left(\left\{\left(\varepsilon_{D}^{W}+\alpha \varepsilon_{S}^{S S A}\right) /(1-\alpha)\right\}+\varepsilon_{S}^{R o W}\right)=-\gamma_{O} a^{\text {RoW }}$

where the superscript RoW denotes rest of world and so $a^{\text {RoW }}$ is TFP growth in the non-SSA region. This expression is quite similar to (2), only now the productivity growth in question only arises in the non-SSA, RoW region.

Utilizing this equilibrium outcome allows us to solve for the elasticity of net imports into SSA as a function of TFP growth in the rest of the world, yielding the following:

$t / a^{R o W}=100 * d M / Q^{W}=\left[\alpha \varepsilon_{S}^{S S A}+\beta \varepsilon_{D}^{S S A}\right] \gamma_{O}^{R o W}$

where $\gamma_{O}^{R o W}=\left(\varepsilon_{S}^{R o W}+1\right) /\left[\left\{\left(\varepsilon_{D}^{W}+\alpha \varepsilon_{S}^{S S A}\right) /(1-\alpha)\right\}+\varepsilon_{S}^{R o W}\right]$. Not surprisingly, the elasticity of virtual technology trade with respect to RoW productivity growth, $t / a^{R o W}$, depends on all of the supply and demand elasticities in the two region model, as well as the relative size of SSA and in the global food economy, through the (negative of the) price multiplier on RoW TFP growth: $\gamma_{O}^{\text {RoW }}$. Once the world price effect is determined, then the trade elasticity is increasing in the price elasticities of demand and supply in the SSA region. If consumers and producers in this region are highly responsive to price, then the elasticity of virtual technology trade will be larger.

In the quantitative trade model developed in the next section, we will elicit the magnitude of this elasticity. In an empirical context, we will see that the virtual trade in technology elasticity also depends critically on the degree to which the SSA food economy is integrated into global markets. The foregoing, two region model assumes full market integration, but in reality, the extent of SSA integration into world agricultural markets remains limited. Furthermore, in the context of 
a more disaggregated representation of the global economy we expect that virtual technology trade will emanate from just a few highly innovative regions, not the entire rest of world.

\subsection{Implications for Land Use}

For a number of purposes, it will also be useful to consider the impact of new agricultural technologies on land use in agriculture. The change in global cropland as a function of innovations in the RoW region can be expressed at the weighted summation of the change in RoW cropland and the change in cropland in the SSA region:

$$
q_{L}^{W}=\omega q_{L}^{S S A}+(1-\omega) q_{L}^{R o W}
$$

where $\omega$ is the share of SSA in global cropland. Substituting in the equilibrium solution for world prices and the ensuing land supplies, as a function of the TFP change we have:

$$
q_{L}^{W}=-\omega\left(v_{L}^{S S A} / \theta_{L}^{S S A}\right) \gamma_{O}^{R o W} a^{R o W}+(1-\omega)\left(v_{L}^{R o W} / \theta_{L}^{R o W}\right)\left(1-\gamma_{O}^{R o W}\right) a^{R o W}
$$

Clearly land use in the SSA region will fall when TFP in the RoW region rises, since world prices are falling, but land use in the RoW region is ambiguous. If $\gamma_{O}^{\text {RoW }}<1$, then the second term in (8) will be positive and land use will rise in RoW. But this is the same condition for the excess demand elasticity facing producers in RoW to be inelastic. This is also the condition under which land rents rise, and land use expands in the face of TFP improvements.

What about the global change in cropland? Insight into the combined land use changes can be gained by making some simplifying assumptions (see Appendix). If, for example, supply response to commodity prices is the same in both SSA and RoW, then the condition for global cropland to expand in the face of TFP growth in RoW is simply:

$$
(1-\omega) /(1-\alpha)>\left(\varepsilon_{S}+1\right) /\left(\varepsilon_{D}^{W}+\varepsilon_{S}\right)
$$

Where the left-hand side of this expression is equal to the ratio of global crop yields (output per unit area) to RoW crop yields. This tells us that, for global cropland to expand in the wake of RoW 
productivity gains, we require a relative elastic global demand for food $\left(\varepsilon_{D}^{W}>>0\right)$ combined with relatively low yields in RoW $[(1-\omega) /(1-\alpha)]>>1$ so that the combination of expanding food demand and displacement of high yielding crops elsewhere by low yielding production in the innovating region causes RoW land use to expand more than the contraction in SSA. This does not square with the facts, since global food demand is relatively inelastic and yields in SSA are low, relative to RoW. Therefore, we expect, that, with integrated commodity markets, technological innovation in RoW will reduce global land use in crops, thereby benefiting the environment.

\subsection{Adding Natural Resource Conservation}

The final consideration that we bring to bear in this theoretical model is the emerging trend in some of the world's richest economies to use TFP growth to reduce input use in agriculture. This reduces the growth in output in food production in the RoW region, as can be seen in the following expression in which agricultural land and water resources are withdrawn from agriculture through a set of environmental programs, thereby resulting in a backward shift in land supply, $\Delta_{L}$ :

$q_{O}^{R o W}=\varepsilon_{S}^{R o W} p_{O}+\left(\varepsilon_{S}^{R o W}+1\right) a^{R o W}-\Delta_{L}^{R o W}$

From this expression it can be seen that such an environmental program can potentially be large enough to neutralize the growth in output and eliminate the virtual technology trade altogether. Indeed, this has been the case in much of Europe as well as in high income East Asia (Heisey and Fuglie 2018). In the special case where: $\Delta_{L}^{R o W}=a^{R o W}\left(\varepsilon_{s}^{R o W}+1\right)$, these conservation programs fully offset the effect of TFP on output growth. Another way of thinking about this is that regions like the EU can withdraw resources from agriculture up to this point without having an adverse impact on output. However, if TFP growth slows beyond that point, or if the conservation practices are more aggressive, regional output -- at constant world prices -- will fall. 
In the context of the two-region trade equilibrium, the world price change as a function of the combined TFP growth and conservation measures in the non-SSA (RoW) region becomes:

$$
p_{O}=\left[(1-\alpha) \Delta_{L}^{R o W}-(1-\alpha)\left(\varepsilon_{S}^{R o W}+1\right) a^{R o W}\right] /\left[\varepsilon_{D}^{W}+\varepsilon_{S}^{W}\right]
$$

The first term in the numerator (backward supply shift due to conservation measures) offsets some of the price reducing effect of the innovation in RoW and therefore dilutes the amount of virtual technology trade which will follow from the innovations in RoW agriculture.

\section{Quantitative Trade Model}

In order to explore the potential for trade in technology to resolve the Malthusian challenge in SSA, we turn to a numerical implementation of the theoretical framework discussed above. This higher dimensional implementation of the theoretical model allows us to relax a number of critical assumptions. These include: (i) increasing the number of regions to allow for isolation of key sources of technology spillovers (ii) development of explicit R\&D spending scenarios and the ensuing profile of TFP growth across these regions over time, (iii) heterogeneous rates of population and income growth, and (iv) relaxing of the assumption of perfectly elastic supplies of non-land factors of production.

\subsection{Model Dimensions}

The quantitative trade model used here is dubbed SIMPLE: a Simplified International Model of Prices Land use and the Environment, in recognition of the barebones nature of the model (Baldos and Hertel, 2013; Hertel and Baldos, 2016). It has been used to analyze the long run drivers of future food production, prices and land use change (Baldos and Hertel 2013; Hertel, Baldos, and van der Mensbrugghe 2016), adaptation to climate change (Baldos and Hertel 2015; Lobell, Baldos, and Hertel 2013), the role of R\&D and productivity growth in ensuring food security and

environmental sustainability (Baldos and Hertel 2014; Hertel, Ramankutty, and Baldos 2014) and the market impacts of reducing food waste and post-harvest losses (Hertel and Baldos 2016). As 
its name suggests, this has been designed around the principle that a model should be no more complex than is absolutely necessary to understand the basic forces governing the global supply and demand for crops, cropland and food prices.

The SIMPLE model disaggregates the world economy into sixteen regions, each producing an aggregate crop commodity using a variable combination of land and nonland inputs (Fig. A1 in supplementary material). Substitution of non-land inputs (e.g., fertilizers, farm labor and machinery) for land in crop production offers scope for endogenous intensification of production, allowing for crop yield growth even in the absence of technological change under increasing scarcity of land. Expansion of cropland requires that the land be bid away from competing uses, with the size of this area response varying across geographic regions. Crop production in SIMPLE has four potential uses: direct consumption, livestock feed, food processing, and biofuel feedstocks. Food demands are price- and income-sensitive, but become more inelastic as per capita incomes rise (Muhammad et al. 2011). Rising incomes also cause consumers to diversify their diets, which, at early stages of economic development, means adding relatively more livestock and processed foods. Production of both these commodities requires crop inputs - the demand for which can be altered by exogenous technological progress in those sectors (e.g., more feed efficient livestock technology).

\subsection{Endogenizing Crop Productivity}

In the crops sector, we allow for endogenous growth in productivity, driven by exogenously specified time paths for investments in agricultural research. To implement this idea, we modify the production function in (1) as follows:

$$
Q_{O}=A_{O} K_{O}^{\delta_{0}} K_{S}^{\delta_{S}}\left(\phi_{L} Q_{L}^{-\rho}+\phi_{N} Q_{N}^{-\rho}\right)^{-1 / \rho}
$$


where initial productivity, $A_{O}$, is enhanced by growth in the stock of own-knowledge capital, $K_{O}$, and spill-in knowledge capital, $K_{S}$. These provide factor-neutral productivity shocks, directly contributing to TFP growth in the region. The parameters $\delta_{o}$ and $\delta_{s}$ are elasticities that specify the percentage change in TFP from a 1\% increase in knowledge capital from a given source.

Knowledge capital $K_{i}$ accumulates from past research expenditures $r_{i}(t)$ in region $i$ according to:

$$
K_{i}=\int_{-\infty}^{t-L} e^{-\lambda(t-g)} r_{i}(g) d g
$$

where $\lambda$ is the knowledge capital depreciation rate and $L$ represents the lag time for research expenditures to mature into useable technologies that are adopted on farms. The general expression in (10) can take on a variety of forms. It weights each past year's research expenditure by a value ranging from 0 to 1 ( 0 when the technology is not yet in use or has been replaced or fully depreciated, and 1 when it is fully operational and adopted). In our application we assume a 35-year research lag structure where the weights have a gamma distribution that reaches a maximum value after 14 years. See Alston et al. (2010) for a discussion of measuring knowledge capital in the context of agriculture.

Sources of data on historical expenditures for public and private agricultural research spending are described in Fuglie (2018), who also reports elasticities estimated by more than 40 studies on how agricultural R\&D affected TFP growth in different regions of the world. These elasticities describe how public and private research within countries, research in other countries, and research by international agricultural research centers, affected agricultural TFP growth in particular countries. From this list, Fuglie (2018) developed a "synthesis” set of R\&D elasticities for major global regions and compared the predicted TFP growth from R\&D spending to actual TFP growth for those regions. Fuglie's (2018) results are reproduced in Figure 4, which give an 
indication of the share of historical TFP growth that can be attributed to R\&D, as opposed to other factors. In developed regions, changes in R\&D knowledge capital explain nearly all of agricultural TFP growth, and R\&D spill-ins are significant. In developing regions and transition economies, R\&D knowledge capital accounts for only part of the observed growth in TFP, and R\&D spill-ins are important only for the LAC region. The CGIAR system of international agricultural research centers, which focuses on improving food crops in low income countries, has had a measurable impact on agricultural productivity across all developing regions. The gap between observed and predicted TFP growth in China, Africa and elsewhere can be explained in part by reforms in these regions that encouraged more efficient utilization of existing resources.

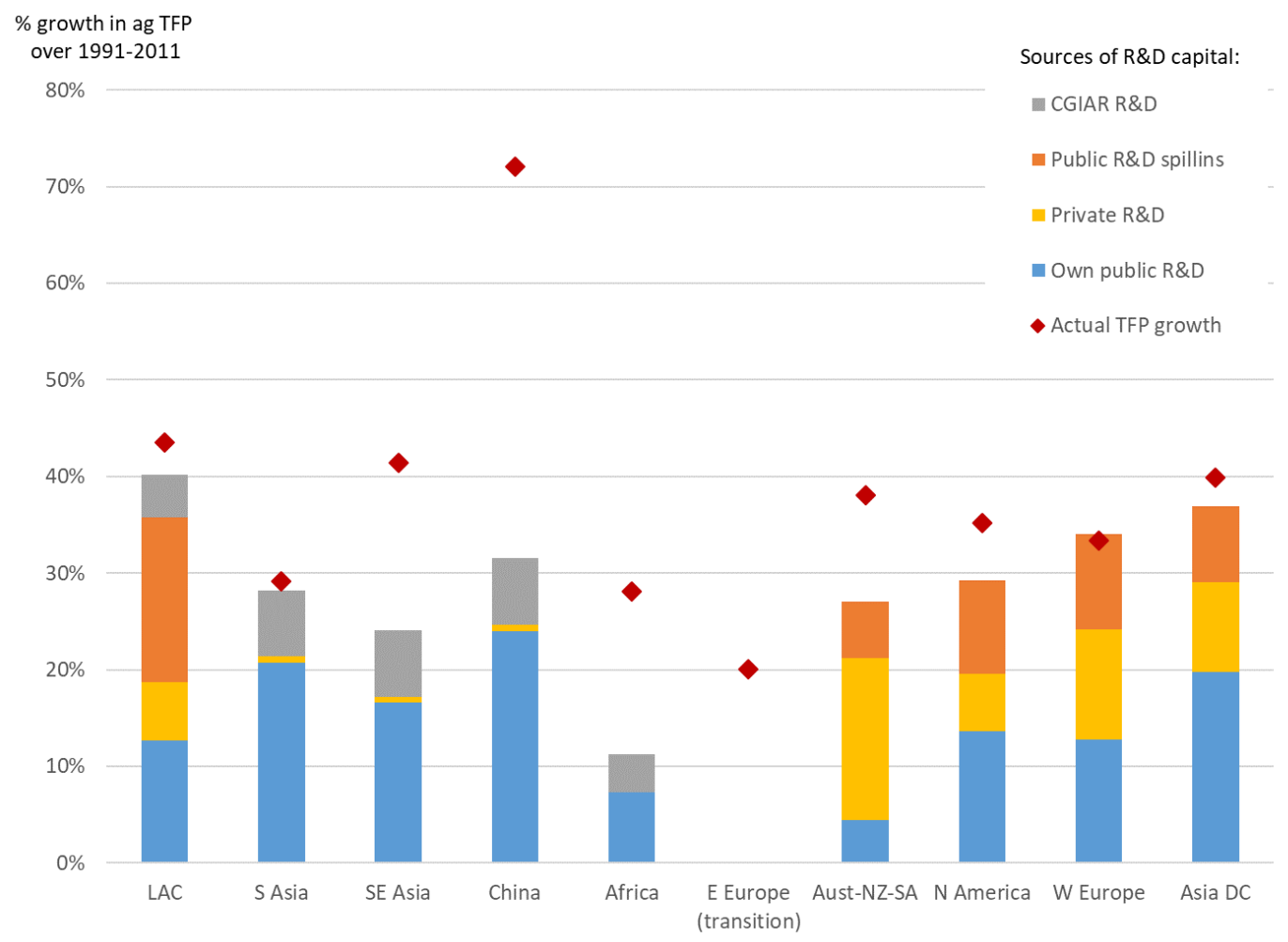

Figure 4. Observed changes in agricultural TFP for major global regions over 1991-2011 and predicted TFP growth from changes in R\&D capital over same period. Source: Fuglie (2018). 


\subsection{Estimating Undernutrition}

Our principal Malthusian metric is the extent of macronutrient malnutrition, specifically, daily caloric intake. Based on estimates from FAO (2012), we postulate a distribution of caloric intake across the population in SSA. The solid line in Figure 5 shows this distribution for the year 2006. By integrating under this density function up to the minimum caloric requirement, we obtain the undernutrition index for that year. Multiplying by total population in the region, we obtain the poverty headcount. Following the approach originally developed for poverty measures by Foster, Greer and Thorbecke (1984), we can also compute the average depth of undernutrition or the 'undernutrition gap'. As income rises, food consumption increases, along with caloric intake, and this density function shifts to the right. The hypothetical 2050 density shown in Figure 5 shows a lower undernutrition headcount ratio in the wake of changes in per capita income, and food prices. However, the absolute number of undernourished people in the region depends on the population growth.

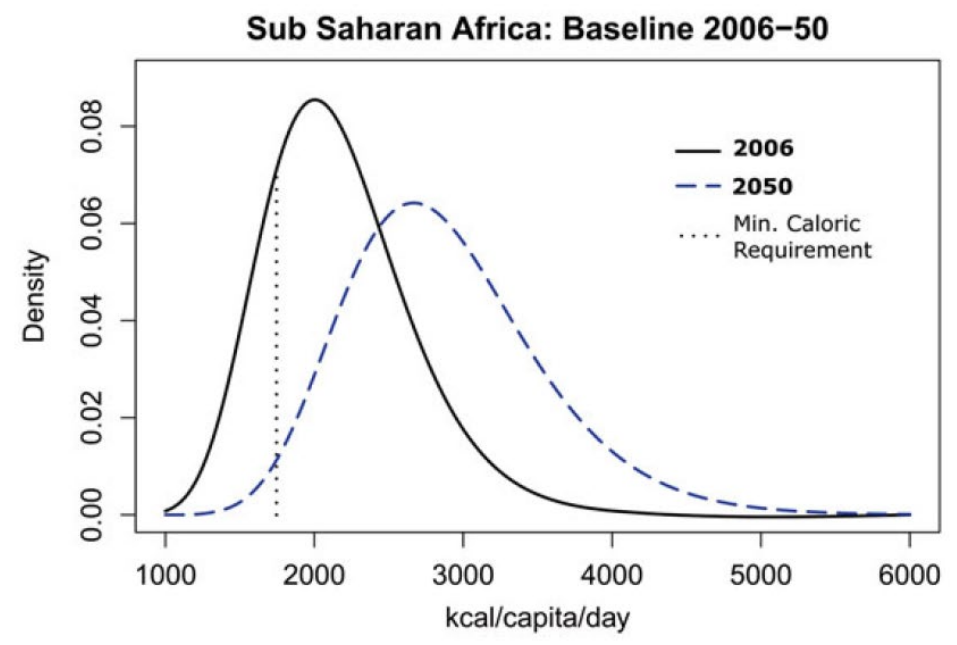

Figure 5 Distribution of caloric consumption for Sub Saharan Africa in 2006 (solid black line) and in 2050 (dashed blue line). The dotted line represents the minimum required daily caloric intake. Source: Authors' calculations using 2006 data from FAO (2012) and 2050 projections from authors' calculations. 


\subsection{International Trade}

The standard implementation of SIMPLE incorporates market segmentation following the idea originally proposed by Armington (1969) who postulated that domestic and imported products were differentiated goods, albeit potentially close substitutes with the degree of substitution determined by a CES function. This trade specification, and subsequent elaborations on this basic CES framework that introduce love of variety, have dominated the empirical trade literature (Hillberry and Hummels 2013) and the CES specification has been shown to dominate the homogeneous product approach in the context of agricultural trade (e.g., Villoria and Hertel, 2011). The CES specification is also consistent with market demand when individual households make a discrete choice between purchasing international vs. domestic commodities and consumers' ideal characteristics are distributed according to the multinomial logit (Anderson, Palma, and Thisse 1989). In this case, the elasticity of substitution is inversely related to the measure of heterogeneity in the underlying population's preferences. So, for example, a country in SSA with a portion of the population in an urban seaport, exposed to international products, and also many people still living in remote rural areas with limited exposure to world markets, would have a lower elasticity of substitution than one in which nearly everyone lived in cities along the coast with ready access to international markets.

We apply the same segmented markets specification to domestic producers where suitable aggregation across agricultural producers with differential international market access gives rise to a Constant Elasticity of Transformation (CET) between goods produced for the domestic and international markets. When many of a country’s farmers face high transport costs and have poor access to world markets, the absolute value of this transformation elasticity is small, and domestic producers are relatively unresponsive to world price changes. On the other hand, when farmers are well- integrated into the world market, we expect a strong supply response to international prices. 
The extent of market segmentation is captured by the elasticities of substitution and transformation between domestic and international goods as well as the initial shares of international goods in the consumption and production bundles. The absolute value of the trade elasticities are set to 3, in keeping with the broad thrust of the empirical evidence for international substitution of crops (Hertel et al. 2007). In the Armington specification, the initial extent of market penetration (the share of demand expenditures on international goods, linked to domestic goods through the CES utility function, and the share of domestic production sold to the global market, linked to local sales through the CET transformation function - see Figure A2) also plays a central role in determining the degree to which the global and regional crop markets are linked. If no international goods are available (zero share), then domestic and international consumer prices will not be linked at all.

\subsection{Model Validation}

SIMPLE has been tested over historical periods via backcasting, focusing on global changes in food production, prices and cropland (Baldos and Hertel 2013), regional output changes (Hertel, Ramankutty, and Baldos 2014; Hertel and Baldos 2016), as well as changes in undernutrition (Baldos and Hertel 2014). Figure 6 summarizes observed changes as well as model outputs over the period 1961-2006. Model outputs are generated using historical changes in population, income as well as agricultural TFP growth (see Table A1). In general, the model does well in capturing the historical changes in crop production and crop price at the global level (actual changes at 196\% and $-23 \%$ vs model output at $183 \%$ and $-23 \%$, respectively). SIMPLE also captures the partitioning of global crop supply growth between global cropland expansion and global average crop yield growth (see Figure A3). However, relative to the global changes the model does less well at capturing historical changes at the regional level (see Figure A4) due to the importance of local and regional policies, civil conflict and many other factors omitted from SIMPLE. This regional 
'fit' could be improved by incorporating additional shifters in the supply and demand functions to reflect these other factors.

Figure 6 also shows the contribution of population, income and agricultural productivity growth to the historical changes output. Here, we see that the simulated increase in global crop production is mainly due to the historic population growth over this period (red bar - left panel, Figure 6). Increased food demand due to population growth results in upward pressure on global crop price (red bar, right panel, Figure 6) but strong growth in agricultural productivity (green bar, right panel, Figure 6) caused food prices over this long run historical period to decline.

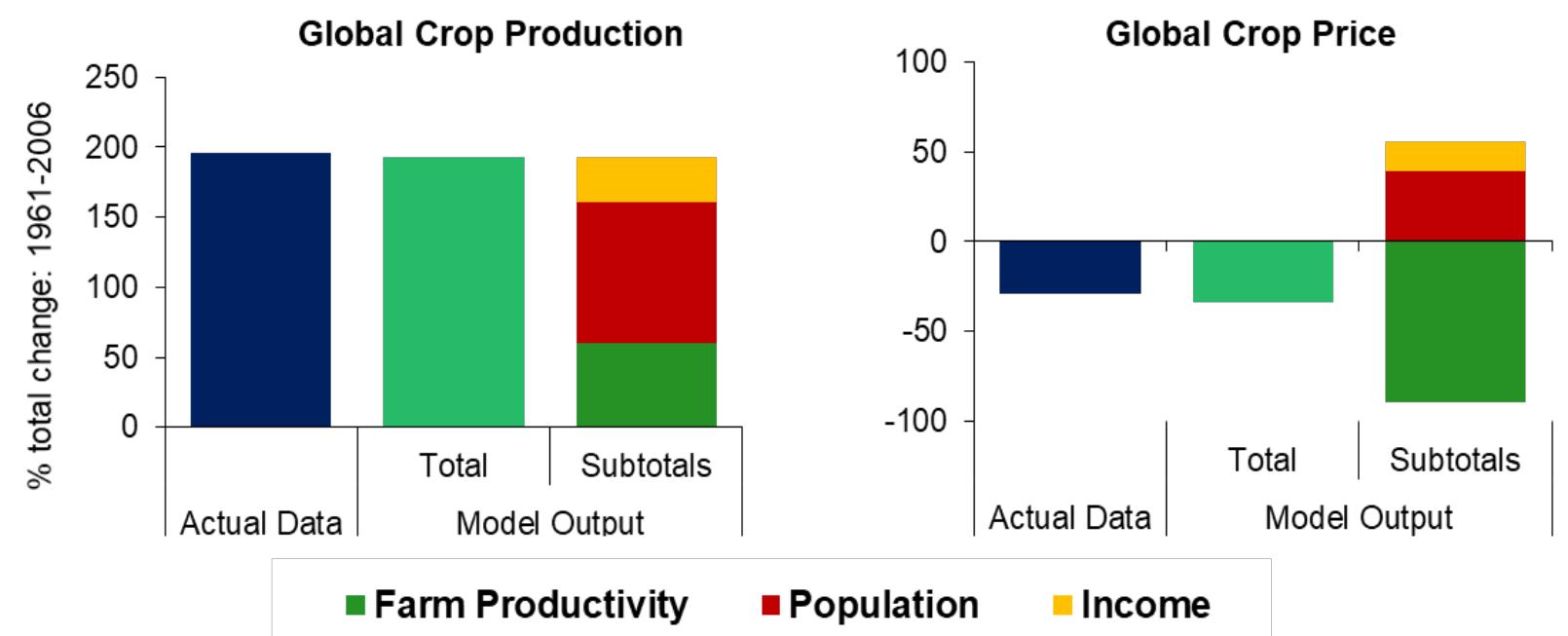

Figure 6. Historical validation and decomposition of key drivers of global crop production and prices. Historical data on crop production and prices are from FAO (2019) and World Bank (2019), respectively. (See also Appendix Table A1.)

\section{Results}

\subsection{Historical Role of Trade in Technology: 1991-2011}

We begin by examining the role of the three different channels through which technology can influence food security in an historical context. Given the long lag linking R\&D spending to knowledge capital, and limitations on our R\&D time series data, our historical analysis of the different channels of technology trade begins in 1991 (recall Figure 4). By combining the findings underpinning figures 4 and 6, we can provide a decomposition of the contributions of technology 
to food price changes in the SSA region over the 1991-2011 period (Figure 7). This shows that the most important channel was direct investment in R\&D within the SSA region, followed by virtual technology trade and CGIAR investments in R\&D. The world market effects of spill-ins among countries outside of SSA, and thereby on SSA prices - labeled here as 'interactions', was relative minor over this historical period.

Historical Drivers of Consumers' Crop Price in SSA: 1991-2006

30

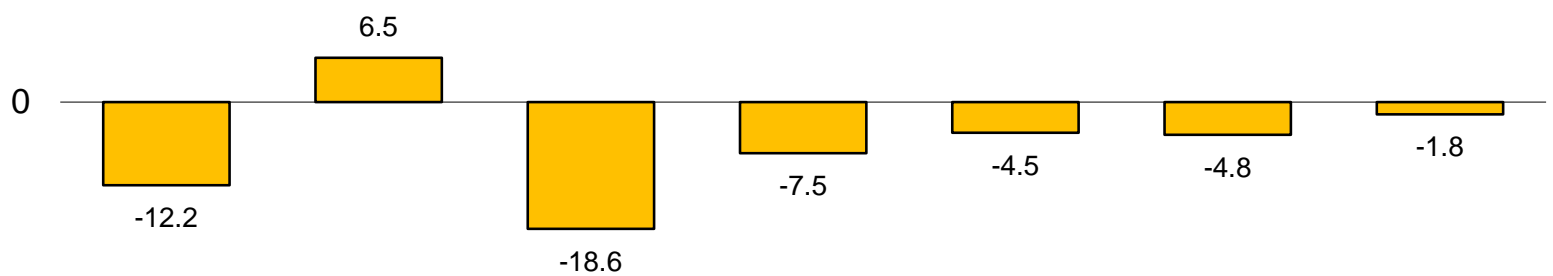

$-30$

\begin{tabular}{|c|c|c|c|c|c|c|}
\hline \multirow[t]{2}{*}{$\begin{array}{l}\text { TOTAL } \\
\text { CHANGE }\end{array}$} & Non-Tech & All Tech & Own Tech & CGIAR & $\begin{array}{c}\text { Virtual Tech } \\
\text { Trade }\end{array}$ & Interactions \\
\hline & \multicolumn{2}{|c|}{ Subtotals } & & \multicolumn{3}{|c|}{ Subtotals: All Tech only } \\
\hline
\end{tabular}

Figure 7. Historical decomposition of consumers' crop price drivers in Sub-Saharan Africa: 19912011. Non-Tech drivers include population and income, as well as TFP growth in non-crop sectors and the crop TFP residual unexplained by R\&D investments in agriculture. All Tech drivers comprise public R\&D in SSA, CGIAR R\&D, Virtual technology trade and Interactions. Virtual technology trade is the combined impact of public and private R\&D spending in non-SSA regions (RoW) and the interactions represent the impact on SSA prices of between regional R\&D spill-ins amongst RoW regions as channeled through virtual technology trade.

\subsection{Future Scenarios}

To understand the potential for trade in technology to alleviate the Malthusian pressures in the SSA region by mid-century, we run a series of six forward-looking experiments as shown in Table 1, where rows correspond to the state of market integration and columns correspond to the extent of technology spillovers. For example, the first cell in this experimental design matrix captures the intersection of historically segmented markets (first row) and historical (low) spillover coefficients (first column). We dub this experiment Seg-LowSpill which we treat as our future baseline 
scenario, since it corresponds to the assumptions made in our historical analysis. In contrast, the diagonally opposing cell is dubbed Int-HighSpill, denoting fully integrated markets (second row) and enhanced spillovers (but without environmental restrictions) (second column), as described in Sections 2 and 3 above. By comparing entries across rows in this matrix we obtain insights into the role of market integration in the determination of technology's impacts on future food prices and undernutrition in Sub Saharan Africa. By contrasting entries across the first two columns in this matrix, we see the effects of enhanced spillovers on direct and virtual technology trade and their consequences for undernutrition in SSA. The final (third) column in this experimental design table corresponds to the case in which environmental restrictions in key non-SSA regions are added to the shocks applied in the second column's experiments. By restricting food supplies in the rest of the world, these policies will indirectly affect SSA prices and undernutrition.

Table 1. Experimental Design

\begin{tabular}{|c|c|c|c|c|}
\hline \multirow{3}{*}{\multicolumn{2}{|c|}{$\begin{array}{l}\text { Experimental } \\
\text { Design }\end{array}$}} & \multicolumn{3}{|c|}{ Technology Spillovers } \\
\hline & & \multirow{2}{*}{$\begin{array}{l}\text { Historical } \\
\text { Spillovers }\end{array}$} & \multicolumn{2}{|c|}{ Enhanced Spillovers } \\
\hline & & & No Environ & With Environ \\
\hline \multirow{2}{*}{ 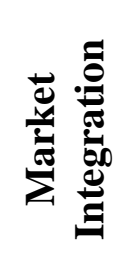 } & $\begin{array}{l}\text { Historical } \\
\text { Segmentation }\end{array}$ & Seg-LowSpill & Seg-HighSpill & Seg-HighSpill-Env \\
\hline & $\begin{array}{c}\text { Full } \\
\text { Integration }\end{array}$ & Int-LowSpill & Int-HighSpill & Int-HighSpill-Env \\
\hline
\end{tabular}

\subsection{Global Baseline Results}

Before taking a closer look at the regional results in SSA, we first examine the changes in key global variables in our future baseline scenario: Seg-LowSpill. Figure 8 shows projected changes in global crop production and prices (upper panel). These projections are generated using baseline assumptions about how population and per capita income as well as agricultural TFP will grow 
between 2006 and 2050 (see Table A2). Under the future baseline, growth rates in TFP for the crops sector are based on expected increases in public R\&D spending in agriculture as well as ‘Historical North’ technology spillovers as defined in Section 4.1.

An important qualification is that we abstract from climate change impacts in these projections. These impacts remain highly uncertain, but within the context of the present framework, adverse climate impacts might best be thought of as 'sand in the gears' of the $\mathrm{R} \& \mathrm{D} /$ productivity production process. In effect the elasticity of productivity with respect to $R \& D$ capital might be reduced in the most severely affected regions. On a global scale, between the present and mid-century, there are both positive impacts (colder regions benefit, as do certain plants that benefit from elevated $\mathrm{CO} 2$ concentrations) as well as negative ones, thereby resulting in offsetting global price impacts. As one moves out further in the century, the negative impacts dominate (IPCC 2014).
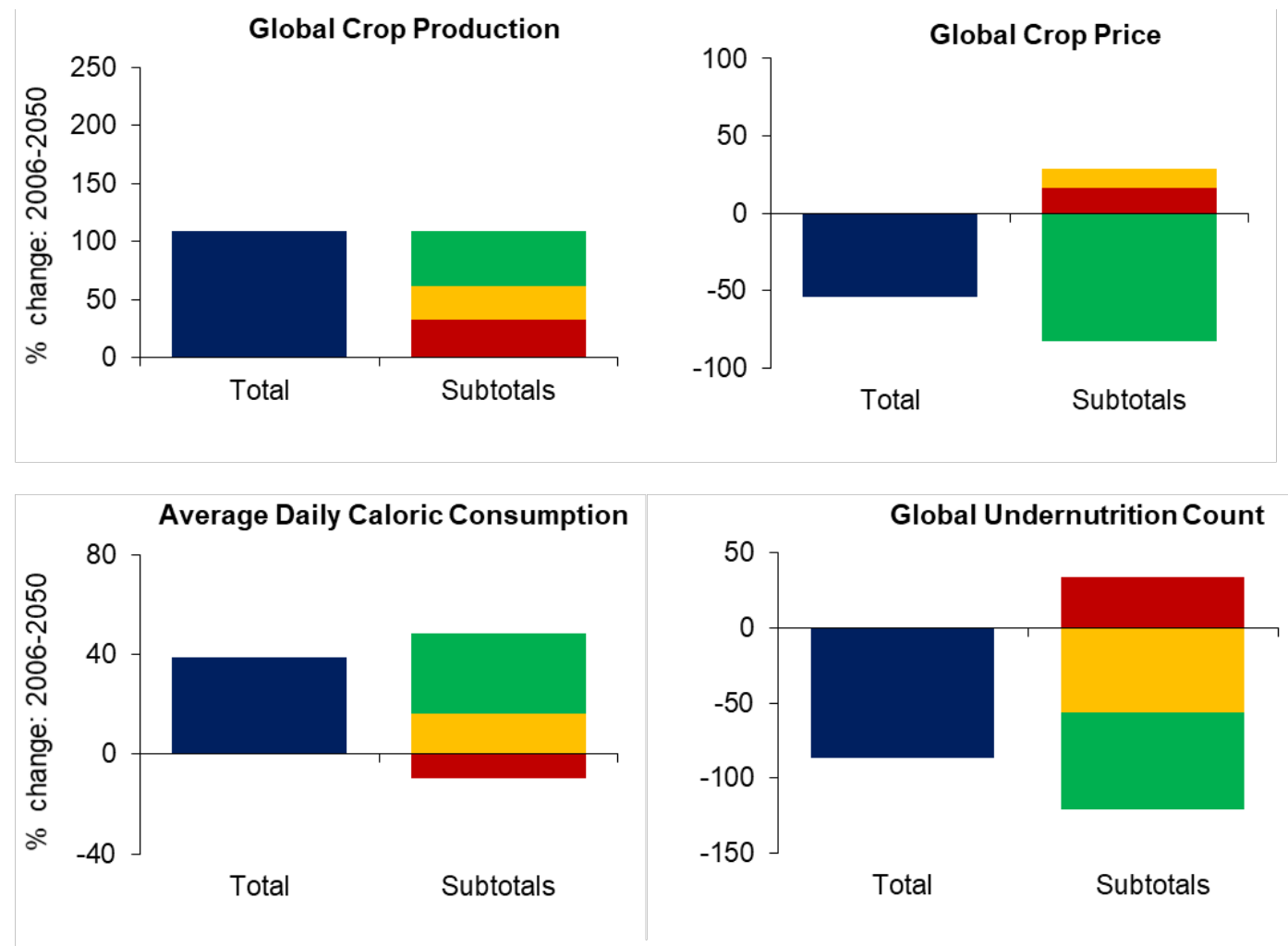

- Population =Income $\quad$ Farm Productivity 
Figure 8. Projected baseline, 2006-2050, assuming segmented markets, historical spillovers and the absence of environmental restrictions on agriculture. The colored bars provide a decomposition of key drivers of global crop production, prices, caloric consumption and non-farm undernutrition headcount. See Appendix Table A1 for more details.

Relative to the historical changes, we see that the future increase in global crop production over 2006-2050 (109\%) is much less rapid (in percentage terms) than the increase over a comparable historical period: 1961-2005 (190\% - see Figure 6). Global food prices are expected to continue their long-term decline (falling by another 39\% from 2006 levels). Key to these outcomes is the anticipated slowdown in demand growth as global population stabilizes (average annual growth of $2.6 \%$ in $1961-2006$ vs $0.8 \%$ in 2006-2050). With this slower population growth, we now see that a rise in the relative contribution of per capita income growth to total food output growth (orange bar - upper left panel, Figure 8). Globally, average caloric consumption is expected to increase by 39\% (mostly through increased consumption of meat and processed food products) while undernutrition count is predicted to fall by almost $87 \%$. Greater food availability due to future improvements in farm productivity leading to increased food affordability, as well as rising per capita incomes, are key to attaining these strong gains in future food security.

\subsection{The Role of Technology in Enhancing Food Security in SSA}

Figure 9 reports four sets of results from our experiments with the two variants of the SIMPLE model: segmented and integrated markets for crop commodities, each considered under two different technology scenarios: historical (low) spillovers and enhanced (high) spillovers. Focusing first on the model with segmented markets and historical spillovers (our 'baseline' version of the current world, Seg-LowSpill), the model projects flat consumer crop prices in SSA over the 2006-2050 period (the far left orange column in Figure 9). The next set of bars report the contribution of population, income and non-crop TFP growth in the global economy, leaving the remaining bars in the left-hand panel of Figure 9 to decompose the impact of R\&D investments in 
agricultural technology (All Tech) into the components identified in the theory section above. The first is the contribution of SSA's own technological innovations on crop prices in the SSA region. This contribution is relatively modest over the future period, as public R\&D spending in the region has been relatively low and is not projected to grow strongly in the coming decades. For example, Fuglie et al. (2019) show that agricultural R\&D spending by SSA countries is far lower than the developing-world average by a number of intensity measures (spending as a percentage of agricultural GDP, spending per hectare of cropland, spending per farm worker, the growth rate in spending over the past several decades). The second set of Tech bars in Figure 9 refer to the impact of CGIAR investments in R\&D. These assume relatively greater importance going forward. The historical record does not show evidence of significant R\&D spillovers into the SSA region (beyond CGIAR) and so there is no direct trade in technology between RoW and SSA in the lefthand panel of Figure 9. The fourth component of this decomposition refers to the impact of virtual technology trade, led by growth in the availability of food in the SSA region due to technological improvements elsewhere in the world. In sharp contrast to the historical period, this is the dominant factor in the baseline experiment wherein market segmentation and historical spillovers are maintained. The fourth and final component of this decomposition is the result of interactions between spillovers amongst regions in RoW and virtual technology trade with SSA. When technology spills over from (e.g.) US to Argentina, and Argentinian producers expand exports, SSA benefits indirectly from the spillovers within RoW through lower world food prices. This interaction effect would not have arisen if the initial spillovers had not taken place. It is facilitated by international commodity trade, but it is quite small in our baseline experiment under segmented markets. 
What would happen if markets become fully integrated while retaining the historical technology spillovers? This is admittedly an extreme case, whereby one price prevails, worldwide, for the composite crop commodity. This scenario is designed to foreshadow future differences in the impact of technology trade, if agricultural markets were to become more globalized. There are clearly many obstacles to achieving greater international integration in agricultural markes, including transportation costs and infrastructure limitations, government policies aimed at maintaining some degree of self-sufficiency in food, and differing sanitary and phyto-sanitary standards. However, the emergence of global supply chains for food is gradually reducing these barriers. It is therefore of some interest to consider this case. Under the Int-LowSpill scenario SSA crop prices fall by about 50\% when markets are integrated (the far-left orange stippled bar). This highlights the critical importance of international trade in determining the future affordability of food in the SSA region in the face of strong growth in population and per capita incomes (NonTech contribution to prices). The mechanism by which this occurs is as follows: When markets are integrated, the upward pressure on SSA food prices owing to this economic growth is spread across the globe. Since the downward price pressure in SSA from technology (All Tech) is quite similar to the segmented case, the net effect is a significant price reduction for SSA consumers.

It is also interesting to contrast results from the Seg-LowSpill baseline experiment with the case wherein commodity markets remain segmented, but technology spillovers are enhanced (SegHighSpill), thereby allowing for low income countries, including those in SSA, to benefit from technological advancements in the emerging economies. These results are displayed in the red bars in the right hand panel of Figure 9. Enhanced spillovers now contribute directly to price reductions via technology trade (SSA spillovers) as well as indirectly through the interaction effect. With greater spillovers amongst developing countries elsewhere, there are significant indirect (virtual) 
benefits to food consumers in the SSA region. When combined, this results in a reduction in food SSA prices of 35\% over the 45 year projections period.

The stippled red bars in the right-hand panel of Figure 9 report the combined impact of integrated markets and enhanced spillovers (Int-HighSpill). The presence of integrated markets spreads effect of the SSA demand-side growth across the world, thereby diminishing the upward price pressure. Meanwhile, given the large and growing role of agriculture $R \& D$ investments in Latin America, China and South Asia, enhanced spillovers from those regions have a significant impact on world prices, contributing to the reduction of consumer prices in SSA under the IntESpill scenario. This combination of market integration and enhanced spillovers generates the most favorable outcome for SSA consumers, with prices dropping by more than two-thirds over the 2006-2050 period.

\section{Future Drivers of Consumers' Crop Price in SSA: 2006-2050 100 \\ Historical North \\ 100 \\ Enhanced Spillovers}

0

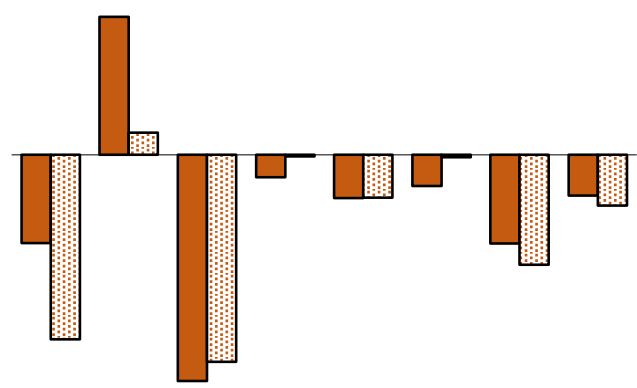

$-100$

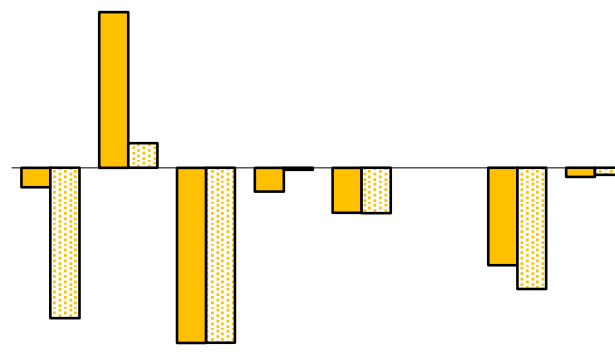

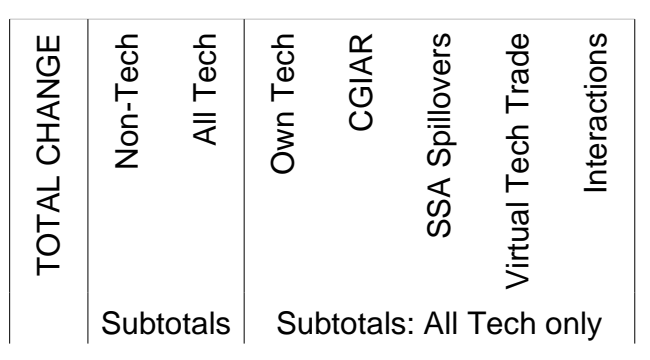

$\square$ Segmented 固Integrated 
Figure 9. Contribution of technological change to the reduction in consumers' crop prices in Sub Saharan Africa: 2006-2050. Non-Tech drivers include population and income, as well as TFP growth in non-crop sectors and the crop TFP residual unexplained by R\&D investments in agriculture. All Tech drivers comprise public R\&D in SSA, CGIAR R\&D, SSA spill-ins (Enhanced spillovers only), Virtual technology trade and Interactions. Virtual technology trade is the combined impact of public and private R\&D spending in non-SSA regions (RoW) and the interactions represent the impact on SSA prices of between regional R\&D spill-ins amongst RoW regions as channeled through virtual technology trade. Source: Authors’ calculations.

One of the key assumptions in our future projections is that the historical relationship between knowledge capital and TFP growth will hold in the future (i.e., the elasticities in equation (12) are unchanging). While this may be reasonable in many cases, we have undertaken sensitivity analysis in two important cases. The first pertains to the productivity of knowledge capital in the SSA region. Historically, $\delta_{O}$ for SSA was just half as large as for the developed regions. This makes it difficult for $R \& D$ investments to have a big impact on future productivity. In the sensitivity analysis presented in the Appendix, we report the impacts of the different types of technology trade on crop prices in SSA for the case where this elasticity for SSA is doubled so that it reaches the values estimated for the more developed regions. This more than doubles the contribution of 'Own Tech' to crop price reduction in SSA, and it leads to a further 5\% reduction in overall prices in the baseline (-12.4\% vs. $-7.6 \%)$ under segmented markets. However, doubling the knowledge capital elasticity for SSA has little impact on crop prices in the region under fully integrated markets.

The other region where we believe a robustness check is in order is Asia - particularly China -- where extremely high rates of current agricultural R\&D investments are leading to rapid growth in knowledge capital and there is some concern about whether these investments will be as productive as in the past. In the Appendix, we consider the impact on consumer prices in SSA under the assumption that $\delta_{O}$ is just half as large for Asia going forward, as was the case in the 
historical simulation. In this case, the impact of virtual technology trade is a smaller driver of crop prices in SSA, although some of this is picked up by other factors so that the total difference in prices under the baseline case is modest (-2.4\% vs. $-7.6 \%)$.

\subsection{The Role of Increased Environmental Emphasis in Other Regions}

Thus far, we have assumed that rising productivity in other regions of the world translates into increasing output and therefore virtual technology trade. However, as we saw in Section 2, in Northern Europe this improved technology has translated into reduced inputs instead of higher output. In particular, by limiting the use of land, water and chemicals in agriculture, the European Union has sought to make farmers stewards of the environment, with farm payments to provide the necessary incentives. The theory developed in Section 3 demonstrates the potential for such environmental restrictions to offset the impact of productivity growth on prices and virtual technology trade. Of course, the extent to which this will actually occur is an empirical question. It depends on the stringency of the environmental restrictions, relative to the rate of productivity growth, the elasticities of supply and demand, as well as the contribution of the restricted region to global output. For this reason, it is important to conduct a quantitative experiment to assess the potential impacts on SSA of stronger environmental standards in RoW.

In this final pair of experiments (recall the last column in Table 1), we assume that the EU approach to restricting inputs used in agriculture spreads to other high income economies, including the US, Canada, Australia, New Zealand, Korea and Japan, as well as to China and Latin America, where environmental pressures are also building. The stringency of these restrictions is such that crop output ceases to grow in all these countries, instead diverting the improved productivity to reduced input usage. Figure 10 decomposes the impact of technology, on the one hand, and region-specific environmental policies, on the other, on consumer crop prices in SSA. 


\section{Future Drivers of Consumers' Crop Price in SSA: 2006-2050}

150

\section{Enhanced Spillovers with Environmental Restrictions}

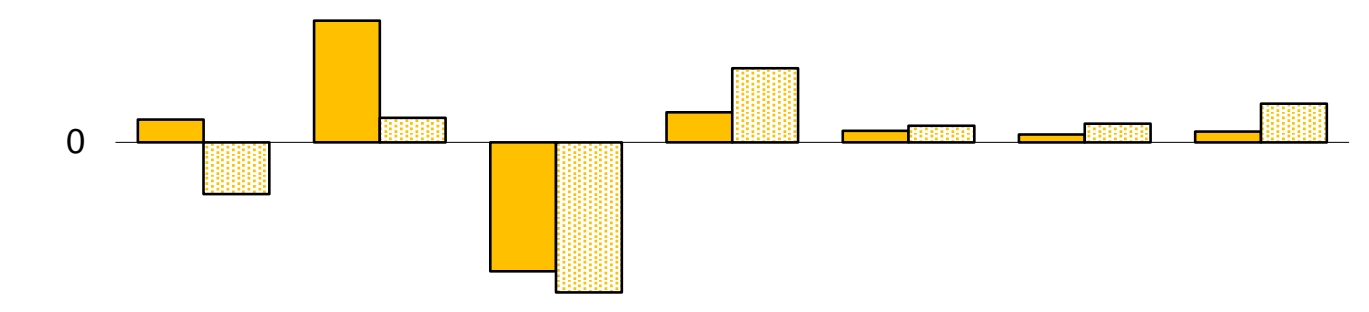

$-150$
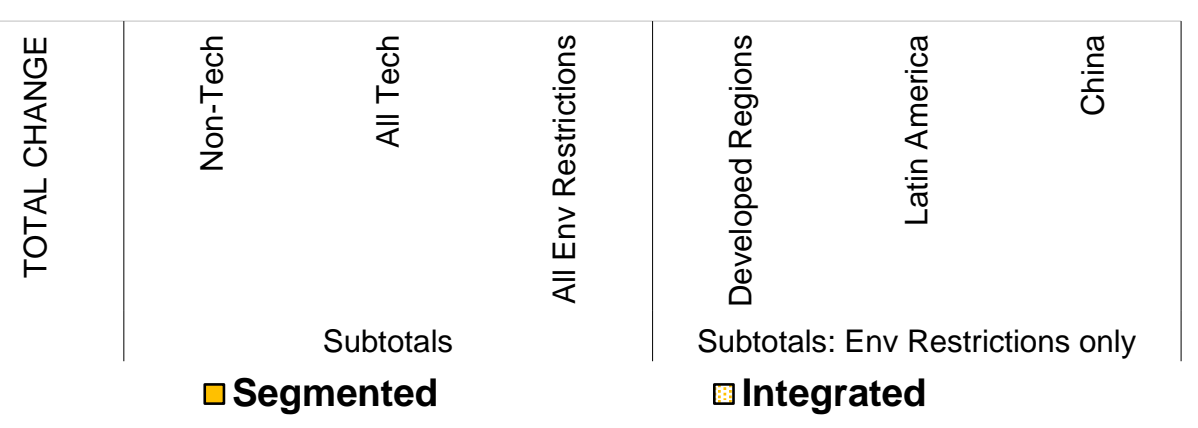

Figure 10. Contribution of technological change and environmental restrictions to consumers' crop prices in Sub Saharan Africa: 2006-2050. Non-Tech drivers include population and income, as well as TFP growth in non-crop sectors and the crop TFP residual unexplained by R\&D investments in agriculture. All Tech drivers comprise public R\&D in SSA, CGIAR R\&D, SSA spill-ins, virtual technology trade and interactions. Environmental restrictions are imposed in the developed regions as well as Latin America and China. Source: Authors' calculations.

The solid orange bars in Figure 10 show the impact of environmental restrictions under segmented markets and high spillovers (Seg-HighSpill-Env). Despite the supply-side benefits of enhanced spillovers, the extensive environmental restrictions result in an $18 \%$ rise consumer prices for crop products in SSA. This stands in sharp contrast to the 25\% reduction under the SegHighSpill experiment, illustrating the indirect impact on SSA food security of widespread environmental constraints on agriculture elsewhere. The environmental constraints on China are the most impactful when it comes to SSA food prices, as China is the world's largest food producer as well as consumer. This is followed - in roughly equal amounts - by the environmental constraints in Latin America, and those in the wealthy economies. 
The final experiment, Int-HighSpill-Env, adds market integration to the mix. So there are now three counterfactual elements to this scenario: enhanced spillovers of technology from emerging economies to other developing regions, environmental constraints in key regions of the world, and agricultural market integration. In this case, the role of market integration in spreading the growing demand-side pressures across the globe is dominant (this shows up in Figure 10 as a reduction in the Non-Tech effect on SSA prices). As a consequence, prices over the 2006-2050 period fall by around one-third in the SSA region.

\section{Consequences for Undernutrition in Sub Saharan Africa}

Combining the baseline growth in income and population (both treated as exogenous in this partial equilibrium framework), with the alternative scenarios for SSA consumer price changes, we can use the framework underpinning Figure 5 to calculate the change in non-farm undernutrition in SSA. By 2050, we expect the majority of the population in Africa will reside in urban areas, with this figure reaching 70\% in Nigeria (UN Population Division 2018). Many of those residing in rural areas will no longer be dependent on agriculture as their primary earnings source. Bearing this in mind, we focus on the potential contribution of lower food prices to the reduction in undernutrition amongst the non-farm households for whom the first-order impact will be a reduction in the cost of their diets. Table 2 reports the percentage change in non-farm undernutrition in SSA under the six scenarios outlined in Table 1, with the food price changes taken from the preceding figures and reported in parentheses in this table.

Judging from the results in Table 2, it appears that the projected increases in per capita income over the future baseline period will contribute to strong reductions in undernutrition, even absent significant price reductions (baseline case, Seg-LowSpill). These food security gains are further strengthened when market integration and/or enhanced technology spillovers are present. Indeed, when those two scenarios are combined (Int-HighSpill), there is a dramatic price reduction 
and non-farm undernutrition is virtually eliminated in the region. Amongst our scenarios, only the case with sharp environmental restrictions in key producing regions outside of SSA results in higher prices and significantly dampens the food security gains in SSA reported in Table 2.

What about on-farm undernutrition? Here, the situation is considerably more complicated. Crop prices also drive farm household income and rural wages. Furthermore, these income changes will depend on whether or not the farm in question participates in the technology improvement, as well as the extent of household income diversification. The latter, in turn can vary greatly by country (Hertel 2016). However, we can say something meaningful about the most extreme cases. For those households that are isolated from markets and fully self-sufficient, developments elsewhere will not play a role. To the extent that these households can be reached with improved technology, local innovations will translate directly into increased production, increases in consumption and potentially entry into commercial sales of their products.

Table 2. Percentage change in non-farm undernutrition headcount in SSA under six scenarios

\begin{tabular}{|c|c|c|c|c|}
\hline \multirow{3}{*}{\multicolumn{2}{|c|}{$\begin{array}{l}\text { \% change in SSA non- } \\
\text { farm undernutrition } \\
\text { (consumers' crop prices): } \\
2006-2050\end{array}$}} & \multicolumn{3}{|c|}{ Technology Spillovers } \\
\hline & & \multirow{2}{*}{$\begin{array}{l}\text { Historical } \\
\text { Spillovers }\end{array}$} & \multicolumn{2}{|c|}{ Enhanced Spillovers } \\
\hline & & & $\begin{array}{l}\text { No Environment } \\
\text { Restrictions }\end{array}$ & $\begin{array}{c}\text { With Environmental } \\
\text { Restrictions }\end{array}$ \\
\hline \multirow{2}{*}{ 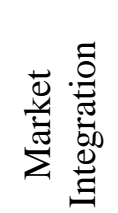 } & $\begin{array}{c}\text { Historical } \\
\text { Segmentation }\end{array}$ & $-72.9(-7.6)$ & $-86.9(-34.6)$ & $-57.8(+16.0)$ \\
\hline & Full Integration & $-96.0(-58.9)$ & $-98.6(-72.3)$ & $-88.1(-36.2)$ \\
\hline
\end{tabular}

The figures give the percentage change between 2006 and 2050 in the share of the non-farm population consuming fewer than adequate calories. (The figures in parenthesis indicate the percentage change in the consumer price of food crops.) See Table 1 for a description of the six scenarios.

At the other extreme, those farm households that are fully integrated into world markets will face essentially exogenous prices. In this case all of the benefits of the local improved technology will be passed back to the suppliers of farm inputs. To the extent that farm-owned factors of production are in relatively inelastic supply, these will attract the rents associated with 
domestic R\&D-driven TFP gains. However, as these farm households will be in direct competition with farmers around the world, the consequences of falling behind in the global R\&D landscape will be extremely costly, as technological innovations in RoW will reduce prices, and hence farm incomes, for the fully integrated farm households.

It is reasonable to expect that the economic position of most SSA farmers in 2050 will lie somewhere between the two extremes of autarky and full integration. In this case, the impact of local TFP growth on returns to farm-owned factors of production will hinge on the excess demand elasticity which producers face. This, in turn, will depend on the price elasticities of demand in local and global markets - as well as, more importantly, the extent of market integration and the supply response in the rest of the world. If the excess demand elasticity facing SSA farmers is less than one, then the derived demand for farm-owned factors of production will fall as TFP in SSA improves, as will their factor returns (see Appendix).

While modeling individual household types is beyond the scope of this paper, these types of questions have received the attention of previous authors who looked at the impact of higher world food prices on poverty in the wake of the food price crisis of the early 2000's. Headey (2014) examines the impact of these higher food prices on national poverty rates. He considers 300 different poverty 'episodes' and concludes that, across this sample of countries and surveys, higher food prices tended to reduce poverty. The mechanism was as follows: higher prices boost the incomes of the rural poor, both through higher farm incomes and higher wages, and the rural poor have historically dominated the poverty statistics. This, in turn, leads to national level poverty reductions. Ivanic and Martin (2008) reach a similar conclusion in their simulation analysis of the impacts of higher world prices for food on poverty. They find that, in the short run, poverty rises due to higher food costs, while in the longer run, the rural income effect dominates and overall 
poverty tends to fall. The findings in both studies are largely driven by the composition of absolute poverty in the early 2000's when rural households have dominated the global absolute poverty statistics. This is changing with rapid urbanization in virtually every part of the world and a definitive assessment of the national poverty and nutrition impacts in the context of this paper would require accurate projections of the rural vs. urban poverty profiles of key countries in 2050. Lacking this information, we cannot generalize about the nutritional impacts of productivity growth on farm households in SSA.

\section{Consequences for Land Use and the Environment}

An important part of the Malthusian dilemma stems from the limited availability of land for agriculture. Indeed agriculture (including both cropland and pasture) accounts for more than $10 \%$ of the earth's surface (Ramankutty, Foley, and Olejniczak 2002) and it is the main driver of deforestation on the planet (Busch and Ferretti-Gallon 2017). As such, it is responsible for a large portion of biodiversity losses and a significant portion of global greenhouse gas emissions (IPCC 2014). Therefore, it is of considerable interest to examine how investments and trade in agricultural technology affect the quantity of cropland - both regionally and globally.

Table 3 reports the percentage changes in SSA cropland under the six scenarios explored above. (Global results are reported in parentheses.) Under the baseline scenario, with market segmentation (first row of results), cropland expands by about one-quarter in the SSA region as a result of the strong growth in regional demand, fueled both by growing population and dietary upgrading in light of the growing per capita incomes. This growth in cropland is significantly mitigated in the presence of enhanced technology spillovers (second column), although these environmental gains are more than offset when the developed and emerging economies implement stronger environmental policies (final column), thereby shunting some of the environmental burden of feeding the world to SSA. The cropland change in SSA is quite 
different under integrated markets (second row). With rapid productivity growth in RoW, as a consequence of strong R\&D investments, SSA producers become less competitive over time and output and cropland fall sharply, except for the case where environmental restrictions are put in place in the RoW region.

Table 3. Percentage change in SSA cropland cover under the six scenarios

\begin{tabular}{|c|c|c|c|c|}
\hline \multirow{3}{*}{\multicolumn{2}{|c|}{$\begin{array}{l}\text { \% change in SSA } \\
\text { cropland cover: } \\
\text { 2006-2050 (global } \\
\text { change in parentheses) }\end{array}$}} & \multicolumn{3}{|c|}{ Technology Spillovers } \\
\hline & & \multirow[b]{2}{*}{$\begin{array}{l}\text { Historical } \\
\text { Spillovers }\end{array}$} & \multicolumn{2}{|c|}{ Enhanced Spillovers } \\
\hline & & & $\begin{array}{l}\text { No Environment } \\
\text { Restrictions }\end{array}$ & $\begin{array}{l}\text { With Environmental } \\
\text { Restrictions }\end{array}$ \\
\hline \multirow{2}{*}{ 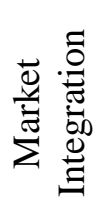 } & $\begin{array}{c}\text { Historical } \\
\text { Segmentation }\end{array}$ & $27.2(0.3)$ & $15.9(-5.5)$ & 30.4 (2.3) \\
\hline & Full Integration & $-37.0(-10.5)$ & $-45.2(-18.0)$ & $-4.2(-30.4)$ \\
\hline
\end{tabular}

The figures give the percentage change between 2006 and 2050 in cropland cover in the SSA region (and global change in parentheses) under six combinations of market integration, spillovers and environment regulations.

Global cropland change is negligible under segmented markets, as expansion in SSA is offset by contraction in RoW where population growth slows, and even declines in some cases, and consumers of food are largely satiated. Under integrated markets, since yields are higher in RoW, the relatively stronger TFP growth in that region allows global cropland to fall quite sharply as production shifts from the low yielding SSA region to higher yielding regions elsewhere (recall equation (9)). This reduction in global cropland is accentuated under integrated markets when land retirement policies are implemented in high income and emerging economies.

\section{Summary and Conclusions}

The recent rise in caloric undernutrition in Sub-Saharan Africa is an indication that the Malthusian footrace between food availability and population remains relevant in the world's poorest countries. This has brought greater attention to the role of agricultural technology in ensuring food security in this region. In this paper, we develop a model of technology, food security and 
international trade in which there are three distinct channels for technology to benefit non-farm food security in SSA. The first is via greater direct R\&D investment in the SSA region. This is the primary channel through which the industrialized and newly emerging economies, including Brazil and China, have boosted farm productivity in their own countries, and it has been the main channel influencing historical development in SSA food prices, since 1961. However, the lag between current investments and future productivity can be a long one, and historical neglect of the agricultural research infrastructure as well as civil strife have made the accumulation of knowledge capital in SSA relatively difficult. An alternative is to import technologies from other countries where significant knowledge capital has already been established. Empirical evidence suggests that technology 'spill-ins' from the wealthy economies, largely located in the temperate climatic zones, has hitherto been very limited. However, there is potential for greater success by transferring technologies from emerging tropical economies, such as Brazil, which share similar agro-ecologies in many instances. The third role for technology to resolve the Malthusian dilemma in SSA is through 'virtual technology trade', i.e., importing the benefits of technological investments made elsewhere through lower cost food imports.

In order to assess the relative contribution of each technology channel to non-farm food security in Africa, we employ a partial equilibrium, quantitative trade model, augmented by a dynamic relationship between R\&D investments, knowledge capital and agricultural productivity. Not surprisingly, we find that the importance of the three technology-food security linkages varies depending on the extent of global market integration. With fully integrated agricultural markets, virtual technology trade is far and away the most important vehicle for reducing non-farm undernutrition in the SSA region. Given the dominance of R\&D capacities outside the SSA region, if there were no trade frictions, this partial equilibrium perspective suggests that it might make 
sense for SSA to import much of its food requirements. Of course, in order to afford these imports, the region must increase exports of other goods and services. A deeper investigation of the future comparative advantage of the SSA region requires a general equilibrium approach, which is beyond the scope of the current paper.

In practice, the world is a long way from integrated markets for agricultural products. Nonetheless, even with the current state of food trade friction, we find that virtual technology will likely eclipse domestic $R \& D$ as the most important vehicle for reducing non-farm undernutrition in Africa between the present and 2050. However, investments in agricultural R\&D by SSA countries can play a significant role as well. And, if SSA researchers can successfully adapt technologies from the emerging markets, this spill-in effect could rival in importance their own $R \& D$ investments as well as those by the CGIAR system. Furthermore, we find there is significant interaction between technology spill-ins in the rest of the world and virtual technology trade when it comes to alleviating hunger in Africa.

Given the importance of agricultural output growth in the rest of the world for SSA's food security - via virtual trade in technology -- we also explore the consequences of more widespread adoption of the Northern European approach to the agriculture-environment interface. Rather than allowing farm productivity growth to be translated into increased food production, Northern Europe has used this opportunity to withdraw resources from agriculture, resulting in a relatively flat farm output profile since 1990. We examine the impact on 2050 non-farm undernutrition in SSA of strengthened environmental restrictions in the richest economies, as well as China and Latin America, such that their production profile, between the present and mid-century, remains flat. This results in higher food prices in SSA (compared to the baseline) and a lesser reduction in 
non-farm undernutrition, as well as far greater rates of cropland conversion SSA. Under this

scenario, much of the environmental burden of feeding the world is shunted to Africa.

\section{References}

Abbott, Philip, Chris Hurt, and W.E. Tyner. 2011. “What’s Driving Food Prices in 2011?” Issue Report. Farm Foundation.

Adamopoulos, T., L. Brandt, J. Leight, and D. Restuccia. 2017. "Misallocation, Selection, and Productivity: A Quantitative Analysis with Panel Data from China.” NBER Working Paper 23039, National Bureau of Economic Research, Cambridge, MA. doi: 10.3386/w23039.

Alexandratos, Nikos. 2009.World Food and Agriculture to 2030/2050. Highlights and Views from Mid-2009. Paper for the Expert Meeting on "How to Feed the World in 2050," FAO, Rome, 24-26 June 2009 (revised 25 July 2009).

Alexandratos, Nikos, and Jelle Bruinsma. 2012. World Agricultural Towards 2030/2050: The 2012 Revision. ESA Working Paper No. 12-03, FAO, Rome.

Ahmed, S.A., Thomas W. Hertel, and Ruben Lubowski. 2008. "Calibration of a Land Cover Supply Function Using Transition Probabilities.” GTAP Research Memorandum 14. West Lafayette, Indiana, USA: Center for Global Trade Analysis, Department of Agricultural Economics, Purdue University. http://www.gtap.agecon.purdue.edu/resources/res_display.asp?RecordID=2947.

Allan, J. A. 1998. "Virtual Water: A Strategic Resource Global Solutions to Regional Deficits." Groundwater 36 (4): 545-46. https://doi.org/10.1111/j.1745-6584.1998.tb02825.x.

Alston, Julian M., Jennifer S. James, Matthew A. Andersen, and Philip G. Pardey. 2010. Persistence Pays: U.S. Agricultural Productivity Growth and the Benefits from Public $R \& D$ Spending. Natural Resource Management and Policy 34. Springer New York. http://link.springer.com/chapter/10.1007/978-1-4419-0658-8_8.

Anderson, Simon P., André De Palma, and Jacques-François Thisse. 1989. "Demand for Differentiated Products, Discrete Choice Models, and the Characteristics Approach.” The Review of Economic Studies 56 (1): 21-35. https://doi.org/10.2307/2297747.

Armington, Paul S. 1969. "A Theory of Demand for Products Distinguished by Place of Production (Une Théorie de La Demande de Produits Différenciés d’après Leur Origine) (Una Teoría de La Demanda de Productos Distinguiéndolos Según El Lugar de Producción).” Staff Papers (International Monetary Fund) 16 (1): 159-78. https://doi.org/10.2307/3866403.

Baldos, U.L.C., and Thomas W. Hertel. 2013. "Looking Back to Move Forward on Model Validation: Insights from a Global Model of Agricultural Land Use.” Environmental Research Letters 8 (3): 034024. https://doi.org/10.1088/1748-9326/8/3/034024.

— 2014. "Global Food Security in 2050: The Role of Agricultural Productivity and Climate Change.” Australian Journal of Agricultural and Resource Economics. https://doi.org/10.1111/1467-8489.12048. . 2015. "The Role of International Trade in Managing Food Security Risks from Climate Change.” Food Security 7 (2): 275-90. https://doi.org/10.1007/s12571-015-0435-z. 
. 2016. "Debunking the 'New Normal': Why World Food Prices Are Expected to Resume Their Long Run Downward Trend.” Global Food Security 8 (March): 27-38. https://doi.org/10.1016/j.gfs.2016.03.002.

Baldos, U.L.C., Frederi G. Viens, Thomas W. Hertel, and Keith Fuglie. 2019. "R\&D Spending, Knowledge Capital, and Agricultural Productivity Growth: A Bayesian Approach.” American Journal of Agricultural Economics 101 (1): 291-310.

Boserup, Ester. 1965. The Conditions of Agricultural Growth: The Economics of Agrarian Change Under Population Pressure. London: Allen \& Unwin.

Caselli, F. 2005. “Accounting for Cross-country Income Differences.” Chapter 9 in Handbook of Economic Growth, Vol. 1A (eds., P. Aghion and S. N. Durlauf), pp. 679-741. Amsterdam: Elsevier.

Diewert, W.E. 1981. "The Comparative Statics of Industry Long-Run Equilibrium.” The Canadian Journal of Economics / Revue Canadienne d'Economique 14 (1): 78-92.

Eberhardt, Markus, and Francis Teal. 2013. "No Mangoes in the Tundra: Spatial Heterogeneity in Agricultural Productivity Analysis*.” Oxford Bulletin of Economics and Statistics 75 (6): 914-39. https://doi.org/10.1111/j.1468-0084.2012.00720.x.

“Ethiopia Population 2019 (Demographics, Maps, Graphs).” n.d. Accessed May 28, 2019. http://worldpopulationreview.com/countries/ethiopia-population/.

FAO. 2012. FAO Food Security Statistics. Accessed 2012. http://www.fao.org/economic/ess/en/. FAO. 2019. FAOSTAT Statistical Database. Accessed 2019 http://faostat.fao.org/.

FAO, IFAD, UNICEF, WFP, and WHO. 2019. "The State of Food Security and Nutrition in the World 2019: B Safeguarding Against Economic Slowdowns and Downturns.” Rome, Italy: FAO. http://www.fao.org/state-of-food-security-nutrition/en/.

Foster, James, Joel Greer, and Erik Thorbecke. 1984. “A Class of Decomposable Poverty Measures.” Econometrica 52 (3): 761-66. https://doi.org/10.2307/1913475.

Fuglie, Keith. 2012. "Productivity Growth and Technology Capital in the Global Agricultural Economy.” In Productivity Growth In Agriculture: An International Perspective, edited by Keith Fuglie, Sun Ling Wang, and V Eldon Ball, 335-68. Cambridge, MA, USA: CAB International.

Fuglie, Keith. 2018. "R\&D Capital, R\&D Spillovers, and Productivity Growth in World Agriculture.” Applied Economic Perspectives and Policy 40 (3): 421-44. https://doi.org/10.1093/aepp/ppx045.

Fuglie, Keith, Madhur Gautam, Aparajita Goyal, and William Maloney. 2019. Harvesting Prosperity: Technology and Productivity Growth in Agriculture. Washington, DC: World Bank.

Fuglie, Keith, and Nicholas Rada. 2013. Resources, Policy and Agricultural Productivity in SubSaharan Africa. Economic Research Report 145, Economic Research Service, U.S. Department of Agriculture, Washington, DC, February.

Gurgel, Angelo, John M. Reilly, and Sergey Paltsev. 2007. "Potential Land Use Implications of a Global Biofuels Industry.” Journal of Agricultural \& Food Industrial Organization, Journal of Agricultural \& Food Industrial Organization 5 (2): 1-36. http://ideas.repec.org/a/bpj/bjafio/v5y2007i2n9.html.

Hayami, Yujiro, and Vernon W. Ruttan. 1985. Agricultural Development: An International Perspective. Baltimore: Johns Hopkins University Press.

Headey, Derek. 2014. “Food Prices and Poverty Reduction in the Long Run.” IFRPI Discussion Paper 1331. http://ebrary.ifpri.org/cdm/ref/collection/p15738coll2/id/128056. 
Heisey, Paul, and Keith Fuglie. 2018. Agricultural Research Investment and Policy Reform in High Income Countries. Economic Research Report 249. Economic Research Service, U.S. Department of Agriculture, Washington, DC, May.

Hertel, Thomas W., and U.L.C. Baldos. 2016. "Attaining Food and Environmental Security in an Era of Globalization.” Global Environmental Change 41 (November): 195-205. https://doi.org/10.1016/j.gloenvcha.2016.10.006.

Hertel, Thomas W., David Hummels, Maros Ivanic, and Roman Keeney. 2007. "How Confident Can We Be in CGE-Based Assessments of Free Trade Agreements?" NBER Working Paper 10477, National Bureau of Economic Research, Cambridge, MA.

Hertel, Thomas W, Navin Ramankutty, and U.L.C. Baldos. 2014. "Global Market Integration Increases Likelihood That a Future African Green Revolution Could Increase Crop Land Use and CO2 Emissions.” Proceedings of the National Academy of Sciences 111 (38): 13799-804.

Hertel, Thomas W. 2016. “Food Security under Climate Change.” Nature Climate Change 6 (1): 10-13. https://doi.org/10.1038/nclimate2834.

Hertel, Thomas W., Uris L.C. Baldos, and Dominique van der Mensbrugghe. 2016. "Predicting Long Term Food Demand, Cropland Use and Prices.” Annual Review of Resource Economics 8: 417-41.

Hillberry, Russell, and David Hummels. 2013. "Chapter 18 - Trade Elasticity Parameters for a Computable General Equilibrium Model.” In, Handbook of Computable General Equilibrium Modeling, Volume 1 (eds., P.B. Dixon and D.W. Jorgenson). Amersterdam: Elsevier. Pp. 1213-1269.

INS/Niger, Institut National de la Statistique-, and I. C. F. International. 2013. "Niger Enquête Démographique et de Santé et à Indicateurs Multiples (EDSN-MICS IV) 2012,” September. https://dhsprogram.com/publications/publication-FR277-DHS-FinalReports.cfm.

IPCC. 2014. Climate Change 2014: Impacts, Adaptation, and Vulnerability. In, Contribution of Working Group II to the Fourth Assessment Report of the Intergovernmental Panel on Climate Change. Cambridge, United Kingdom and New York, NY, USA: Cambridge University Press.

Ivanic, Maros, and Will Martin. 2008. "Implications of Higher Global Food Prices for Poverty in Low-Income Countries.” Agricultural Economics 39 (November): 405-16. http://www.blackwellpublishing.com/journal.asp?ref=0169-5150\&site=1.

Johnson, Daniel K. N., and Robert E. Evenson. 1999. "R\&D Spillovers to Agriculture: Measurement and Application.” Contemporary Economic Policy 17 (4): 432-56. https://doi.org/10.1111/j.1465-7287.1999.tb00695.x.

Lin, Justin Yifu. 1992. "Rural Reforms and Agricultural Growth in China.” American Economic Review 82 (1): 34-51.

Lobell, David B, Uris L.C. Baldos, and Thomas W. Hertel. 2013. "Climate Adaptation as Mitigation: The Case of Agricultural Investments.” Environmental Research Letters 8. https://doi.org/doi:10.1088/1748-9326/8/1/015012.

Magrini, Emiliano, Jean Balié, and Cristian Morales-Opazo. 2018. "Price Signals and Supply Responses for Staple Food Crops in Sub-Saharan Africa.” Applied Economic Perspectives and Policy 40 (2): 276-96. https://doi.org/10.1093/aepp/ppx037.

Muhammad, Andrew, James L. Seale Jr., Birgit Meade, and Anita Regmi. 2011. "International Evidence on Food Consumption Patterns: An Update Using 2005 International 
Comparison Program Data.” Technical Bulletin TB-1929. Washington, D.C., USA:

Economic Research Service, US Department of Agriculture. http://www.ers.usda.gov/Publications/TB1929/.

Nelson, Gerald C., Mark W. Rosegrant, Jawoo Koo, Richard Robertson, Timothy Sulser, Tingju Zhu, C. Ringler, et al. 2010. "The Costs of Agricultural Adaptation to Climate Change.” Discussion Paper 4. Washington D.C., USA: World Bank.

OECD. 2001. "Market Effects of Crop Support Measures.” Paris, France: OECD. . 2011. Evaluation of Agricultural Policy Reforms in the European Union. https://doi.org/10.1787/9789264112124-en.

Pingali, Prabhu L. 2012. "Green Revolution: Impacts, Limits, and the Path Ahead.” Proceedings of the National Academy of Sciences, July. https://doi.org/10.1073/pnas.0912953109.

UN Population Division. 2015. “World Population Prospects: The 2015 Revision.” New York , USA: Population Division of the Department of Economic and Social Affairs of the United Nations Secretariat. http://esa.un.org/unpd/wpp/index.htm.

—. 2018. "World Urbanization Prospects: 2018.” 2018. https://population.un.org/wup/Country-Profiles/.

USDA-ERS. 2019. “International Agricultural Productivity.” On-line database. 2019. https://www.ers.usda.gov/data-products/international-agricultural-productivity/.

Villoria, Nelson B., and Thomas W. Hertel. 2011. "Geography Matters: International Trade Patterns and the Indirect Land Use Effects of Biofuels.” American Journal of Agricultural Economics 93 (4): 919-35. https://doi.org/10.1093/ajae/aar025.

von Lampe, Martin, Dirk Willenbockel, Helal Ahammad, Elodie Blanc, Yongxia Cai, Katherine Calvin, Shinichiro Fujimori, et al. 2014. "Why Do Global Long-Term Scenarios for Agriculture Differ? An Overview of the AgMIP Global Economic Model Intercomparison.” Agricultural Economics 45 (1): 3-20. https://doi.org/10.1111/agec.12086.

World Bank. 2019. “Global Economic Monitor Database.” 2019. http://data.worldbank.org/.

World Development Indicators. 2019. (online datbase). World Bank. https://databank.worldbank.org/source/world-development-indicators

Yang, Hong, and Alexander Zehnder. 2007. "“Virtual Water”: An Unfolding Concept in Integrated Water Resources Management.” Water Resources Research 43 (December): W12301. https://doi.org/10.1029/2007WR006048. 
Appendices for: Trade in Technology: A Potential Solution to the Food Security Challenges of the $21^{\text {st }}$ Century

\author{
By Thomas W. Hertel, Uris L.C. Baldos and Keith O. Fuglie
}

Outline:

A. Theoretical Model

1. Core model

2. Single region results

3. Two region results

4. Adding conservation measures

B. Quantitative Trade Model

C. Additional Results:

1. Benchmark data

2. Backcasting and historical validation

D. Appendix References 


\section{A. Theoretical Model}

Core Model: Box A1 outlines the core, long run partial equilibrium model of agriculture in linearized form (lower case variables denote percentage change in the corresponding upper case (levels) variables.

$$
\begin{array}{|l}
\hline \text { Box A1: A simple, partial equilibrium long run model of agriculture } \\
\begin{array}{ll}
\text { (1) } q_{O}=-\varepsilon_{D} p_{O}+\Delta_{D} & : \text { demand for agricultural output } \\
\text { (2) } p_{O}+a=\sum_{j} \theta_{j}\left(p_{j}-a_{j}\right) & : \text { agricultural entry/exit; zero profits } \\
\text { (3) } q_{N}+a_{N}=q_{O}-a-\sigma\left(p_{N}-a_{N}-p_{O}-a\right) & : \text { demand for non-land inputs } \\
\text { (4) } q_{L}+a_{L}=q_{O}-a-\sigma\left(p_{L}-a_{L}-p_{O}-a\right) & : \text { demand for land input } \\
\text { (5) } p_{j}=0, \forall j \neq L & : \text { supply of non-land inputs } \\
\text { (6) } q_{L}=v_{L} p_{L}-\Delta_{L}^{S} & : \text { supply of land to agriculture }
\end{array}
\end{array}
$$

Notation: all price and quantity variables represent percentage changes in the underlying indexes $q_{O}, q_{j}: \%$ change in long run agricultural output and input $\mathrm{j}$

$a, a_{j}$ : cumulative output-augmenting and input-j augmenting technical change in agriculture $p_{O}, p_{j}: \%$ change in the price of agricultural output and input $j$

$\sigma \geq 0 \quad$ : elasticity of substitution between land and non-land inputs $v_{j} \geq 0, \theta_{j} \geq 0$ : elasticity of supply to agriculture and cost share of input $j$

$\varepsilon_{D} \geq 0$ : price elasticity of demand for agricultural output

$\Delta_{L}, \Delta_{D}$ : shifters in land supply, due to conservation measures, and output demand $\varepsilon_{S}^{X} \equiv \theta_{L}^{-1} v_{L}$ : the extensive margin of supply response (area elasticity wrt commodity price) $\varepsilon_{S}^{I} \equiv \sigma\left(\theta_{L}^{-1}-1\right)$ : the intensive margin of supply response (yield elasticity wrt commodity price) CES production function (upper case variables are levels of corresponding lower case variables): $Q_{O}=A\left(\phi_{L} Q_{L}^{-\rho}+\phi_{N} Q_{N}^{-\rho}\right)^{-1 / \rho}$, where: $\sigma=1 /(1+\rho)$ and $\rho>-1$ 
Equation (1) determines the global demand for food as a function of price (via and constant price elasticity of demand, $\varepsilon_{D}>0$, and exogenous shifts in this demand function, $\Delta_{O}^{D}$, due to growth in population and income, both of which are determined outside this partial equilibrium model. Equations (2) - (4) are a consequence of cost minimizing behavior in the agricultural sector, subject to the CES production function shown at the bottom of Box A1, coupled with free entry/exit into or out of the agricultural sector, thereby ensuring zero profits (2). For the results derived in this paper, the key elements of equations (2) - (4) are the rate of TFP growth ( $a$ ) and the elasticity of substitution between the land and nonland inputs, $\sigma \geq 0$. We do not exploit the input biased technological change terms in this paper. For the derivation of these three equations, see Gohin and Hertel (2003).

Equations (5) and (6) close the factor markets in this model. Given its long run nature, nonland inputs (labor, capital and industrial inputs) are assumed to be in perfectly elastic supply in this partial equilibrium model. By contrast, land (and water) are inelastically supplied to farming, thus giving an upward slope to the partial equilibrium supply curve. The output supply elasticity, $\varepsilon_{S}=\theta_{L}^{-1} v_{L}+\sigma\left(\theta_{L}^{-1}-1\right)$, is therefore a function of the land supply response to land returns, $v_{L}$, translated through the inverse of the cost share of land, $\theta_{L}$, which serves to magnify the impact of commodity price changes on land rents, since the nonland inputs are in perfectly elastic supply and cannot benefit from a commodity price increase. This is the extensive margin of commodity supply.

The other component of the commodity supply response is the intensive margin of supply, $\sigma\left(\theta_{L}^{-1}-1\right)$. It depends critically on the elasticity of substitution between the nonland inputs (e.g., fertilizer) and land. This, too, is a function of the cost share of the inelastically supplied land input. In the case of subsistence agriculture, commercial inputs are likely to be small, capital limited and 
labor abundant, making this cost share large. This translates into a very limited intensive margin of commodity supply response.

Single Region Results: Setting $a_{j}=0$ and substituting (4) into (2), and solving for land rents, we obtain:

$$
p_{L}=\theta_{L}^{-1}\left(p_{O}+a\right)
$$

This is the well-known "magnification effect" in economics whereby any change in output price is magnified as it is transmitted back to the returns to the sector-specific factor, land. Using (1) to eliminate $q_{o}$ from (3), using (2) to eliminate po and equating (5) and (3) to reflect equilibrium in the land market (assuming no environmental conservation measures: $\Delta_{L}=0$ ) leaves us with one equation in one unknown, namely land rents, which depend on all the economic parameters in the model as well as the productivity shock and population growth:

$$
p_{L}=\left[\left(\varepsilon_{D}-1\right) a+\Delta_{D}\right] /\left[v_{L}+\sigma\left(1-\theta_{L}\right)+\theta_{L} \varepsilon_{D}\right]
$$

Plugging (8) into (6), since land supply varies directly with land returns, we have:

$$
q_{L}=v_{L}\left[\left(\varepsilon_{D}-1\right) a+\Delta_{D}\right] /\left[v_{L}+\sigma\left(1-\theta_{L}\right)+\theta_{L} \varepsilon_{D}\right]
$$

Equations (8) and (9) are informative. Firstly, we can see that the impact of technological progress in agriculture on land use is ambiguous. In particular, since all of the parameters in the denominator are non-negative, $a<0 \Rightarrow p_{L}>0$ if, and only if, $\varepsilon_{D}<1$. That is, land returns, and land use will fall following a favorable technological innovation if and only if farm level demand is inelastic. Adding the population growth term, we see that land use will grow in response to the Malthusian factor, but it will grow at less than the rate of population growth due to endogenous intensification of production (nonland substitution for scarce land), as well the price responsiveness of demand. 
Overall, the change in land use remains indeterminate, provided the farm level demand elasticity is less than one.

Equation (8) offers insights into the likely magnitude of such land rental price changes. In particular, the change in land rents, for a given farm level demand elasticity and a given factorneutral productivity shock, will be greater, the smaller the elasticity of land supply $\left(v_{L}\right)$ and the smaller the elasticity of substitution between land and non-land inputs $(\sigma)$. Equation (8) can be re-written in terms of the implied commodity supply elasticity in this model: $\varepsilon_{S}=\theta_{L}^{-1} v_{L}+\sigma\left(\theta_{L}^{-1}-1\right)$, where the first term represents area response to the commodity price change and the second reflects yield response to higher commodity prices. This results in (8'):

$$
p_{L}=\left\{\left[\left(\varepsilon_{D}-1\right) a+\Delta_{D}\right] / \theta_{L}\left[\varepsilon_{S}+\varepsilon_{D}\right]\right\}
$$

Increasing the land supply elasticity or the elasticity of substitution boosts the aggregate supply responsiveness of output, thereby dampening the resulting price changes.

Plugging (8') into (7) and solving for the equilibrium output price change gives:

$$
p_{O}=\left[\Delta_{D}-a\left(\varepsilon_{S}+1\right)\right] /\left[\varepsilon_{S}+\varepsilon_{D}\right]
$$

This is equation (2) in the main text. From this equation, we see that the outcome of the long run Malthusian footrace between supply and demand depends critically on the relative rates of population growth and technological progress, whereby the latter is modulated by the price elasticity of supply. If this elasticity is zero, then the long run evolution of prices is simply dependent on the footrace between demand growth and the rate of technological progress. However, the stronger the supply response in agriculture, the more modest is the rate of TFP growth required to keep prices falling, as TFP growth boosts profitability in agriculture, thereby drawing in additional resources in the form of land and nonland inputs. The resulting equilibrium change in agricultural output can simply be read off the demand schedule: 


$$
q_{O}=-\varepsilon_{D}\left[\Delta_{D}-a\left(\varepsilon_{S}+1\right)\right] /\left[\varepsilon_{S}+\varepsilon_{D}\right]+\Delta_{D}=\left[a \varepsilon_{D}\left(\varepsilon_{S}+1\right)+\varepsilon_{S} \Delta_{D}\right] /\left[\varepsilon_{S}+\varepsilon_{D}\right]
$$

This is equation (3) in the main text. It shows that both TFP growth and population growth will stimulate growth in output, with the magnitude of this increase depending on the size of the demand and supply elasticities.

Two Region Results: In order to understand the impacts of a continental scale technology shock on global commodity prices and undernutrition, we need to factor in not only the changes that arise in the innovating region, but also the response of producers and consumers rest of the world. In the absence of technological spillovers, i.e., keeping the level of technology in the SSA region constant, all of the impacts will be carried through the commodity markets. We call this virtual trade in technology to relate it to the popular literature on virtual trade in water. We investigate the determinants of this virtual technology trade first, then progress to the case where some of the technological gains spillover to the rest of the world - a phenomenon which we dub direct trade in technology.

With minor modifications, we can adapt the model in Box A1 to analyze the impacts of virtual technology trade. Since we will assume in this section that world markets are fully integrated (an assumption that will be relaxed in the quantitative trade model), equation (1) simply becomes global demand. And we distinguish the two regions using the superscripts: SSA and RoW. These are attached to the supply-side variables in equations (2) - (6). In order to assess the impact of virtual trade in technology, we evaluate the percentage change in SSA net imports, relative to global consumption, due to the improvement in technology in the RoW region:

$$
t=100 * d M^{S S A} / Q_{O}^{W}=\beta q o_{D}^{S S A}-\alpha q o_{S}^{S S A}
$$

where $M=Q_{D}^{S S A}-Q_{O}^{S S A}$, reflects net imports into the SSA region, $T=M / Q^{W}$ expresses these net imports as a portion of global supply, $\alpha=Q_{O}^{S S A} / Q^{W}$ is SSA's share of global supply (which equals 
global demand by virtual of global market clearing) and $\beta=Q_{O}^{S S A} / Q^{W}$ is SSA's share of global supply (which equals demand in this equilibrium model). This is equation (4) in the main text.

With integrated world markets, an outward shift in the RoW region's supply curve, in the absence of demand growth, can be represented using the following, reduced form equations:

$$
q_{O}^{\text {RoW }}=\varepsilon_{S}^{\text {RoW }} p_{O}+\Delta_{S}^{\text {RoW }} ; \quad q_{O}^{S S A}=\varepsilon_{S}^{S S A} p_{O} \text { and } q_{O}^{W}=-\varepsilon_{D}^{W} p_{O}
$$

where $\Delta_{S}^{R o W}=\left(\varepsilon_{S}^{R o W}+1\right) a^{R o W}$ and the supply response in each region is a function of the regionspecific factor supply and demand parameters: $\varepsilon_{S}=\theta_{L}^{-1} v_{L}+\sigma\left(\theta_{L}^{-1}-1\right)$. Global market clearing requires that demand equals global supply:

$$
q_{O}^{W}=\alpha q_{O}^{S S A}+(1-\alpha) q_{O}^{R o W}
$$

where $\alpha=Q_{O}^{S S A} / Q_{O}^{W}$ denotes the SSA region's share of global production.

Solving for the equilibrium change in global price in response to the shift in RoW's supply curve:

$-\varepsilon_{D}^{W} p_{O}-\alpha\left(\varepsilon_{S}^{S S A} p_{O}\right)-(1-\alpha) \varepsilon_{S}^{R O W} p_{O}=(1-\alpha) \Delta_{S}^{R O W}$

$p_{O}=-(1-\alpha) \Delta_{S}^{R o W} /\left[\varepsilon_{D}^{W}+\alpha \varepsilon_{S}^{S S A}+(1-\alpha) \varepsilon_{S}^{R o W}\right]=-(1-\alpha) \Delta_{S}^{R o W} /\left[\varepsilon_{D}^{W}+\varepsilon_{S}^{W}\right]$, which is (14)

$$
p_{O}=-(1-\alpha) \Delta_{S}^{R o W} /\left(\varepsilon_{S}^{W}+\varepsilon_{D}^{W}\right)
$$

We can also view this price change in terms of the underlying TFP-induced supply shift and the excess demand elasticity facing the RoW region. Substituting in the expression for the TFPinduced supply shift, we have:

$$
p_{O}=-(1-\alpha)\left(\varepsilon_{S}^{R O W}+1\right) a^{R o W} /\left[\varepsilon_{D}^{W}+\alpha \varepsilon_{S}^{S S A}+(1-\alpha) \varepsilon_{S}^{R O W}\right]
$$

Dividing the numerator and denominator on the right hand side by: $(1-\alpha)$

$$
p_{O}=-\left(\varepsilon_{S}^{R o W}+1\right) a^{R O W} /\left[\left(\varepsilon_{D}^{W}+\alpha \varepsilon_{S}^{S S A}\right) /(1-\alpha)+\varepsilon_{S}^{R O W}\right]=-\gamma_{O}^{R O W} a^{R O W}
$$


where $\gamma_{O}^{R o W}=\left(\varepsilon_{S}^{R o W}+1\right) /\left[\left\{\left(\varepsilon_{D}^{W}+\alpha \varepsilon_{S}^{S S A}\right) /(1-\alpha)\right\}+\varepsilon_{S}^{R o W}\right]$

Note that the first term in the denominator, $\left[\varepsilon_{D}^{W}+\alpha \varepsilon_{S}^{S S A}\right] /(1-\alpha)$, is the elasticity of excess demand facing producers in region RoW. This reflects the residual demand for region RoW's product, once the supply response in the rest of the world is also included. As such, it is larger than the ordinary global price elasticity of demand. Since this combined price response is weighted by the inverse of the share of region RoW's production in the world market grows, as $\alpha \rightarrow 0$ the excess demand elasticity facing these producers collapses to the global price elasticity of demand. Clearly the relative size of the region where technology is improving will play a key role in determining the importance of virtual technology trade.

Having established the impact of a shock to supplies in region RoW on world prices, we can work our way back to the regional outputs and demands:

(16) $q_{O}^{R o W}=-\varepsilon_{S}^{R o W} \gamma_{O}^{R o W} a^{R o W}+\left(\varepsilon_{S}^{R o W}+1\right) a^{R o W}=\left[\left(1-\gamma_{O}^{R o W}\right) \varepsilon_{S}^{R o W}+1\right] a^{R o W}, q_{O}^{S S A}=-\varepsilon_{S}^{S S A} \gamma_{O}^{R o W} a^{R o W}$, $q_{D}^{R o W}=\varepsilon_{D}^{R o W} \gamma_{O}^{R o W} a^{R o W}$, and $q_{D}^{S S A}=\varepsilon_{D}^{S S A} \gamma_{O}^{R o W} a^{R o W}$

And hence the technology-driven change in trade:

(17) $t=100 * d M / Q^{W}=\beta\left(\varepsilon_{D}^{S S A} \gamma_{O}^{R o W} a^{R o W}\right)-\alpha\left(-\varepsilon_{S}^{S S A} \gamma_{O}^{R o W} a^{R o W}\right)=\left[\beta \varepsilon_{D}^{S S A}+\alpha \varepsilon_{S}^{S S A}\right] \gamma_{O}^{R o W} a^{R o W}$

\section{which is equation (6) in the text.}

Substituting in the expression for $\gamma_{O}^{\text {RoW }}$ yields:

(18) $t=100 * d M / Q^{W}=a^{R o W}\left(\varepsilon_{S}^{R o W}+1\right)\left[\beta \varepsilon_{D}^{S S A}+\alpha \varepsilon_{S}^{S S A}\right] /\left(\left\{\left[\varepsilon_{D}^{W}+\alpha \varepsilon_{S}^{R o W}\right] /(1-\alpha)\right\}+\varepsilon_{S}^{R o W}\right)>0$

So the virtual trade in technology is a rather complex function of the regional supply and demand elasticities as well as the shares of the two regions in current demand and supply. As the RoW region looms larger in global supply, $\alpha \rightarrow 0$, and the excess demand elasticity facing that region: $\left\{\left[\varepsilon_{D}^{W}+\alpha \varepsilon_{S}^{R}\right] /(1-\alpha)\right\}$, shrinks and the ensuing price change increases. This has the effect of 
amplifying the demand increase and supply reduction in SSA, therefore increasing the percentage change in technology-driven trade. Conversely, as the RoW (innovating) region shrinks in relative size: $\alpha \rightarrow 1, \gamma_{O} \rightarrow 0$ and the world price change flowing from the technological innovation becomes very small. In this case, the impact on technology-driven trade is small.

Implications for Land Use: We can also deduce the implications for regional and global land use of a productivity shock in the RoW region. This is of interest given the prominent role of agricultural area expansion in terrestrial carbon emissions and biodiversity loss. First, note that the percentage change in global land use can be expressed as a weighted combination of land use change in SSA and in RoW:

(19) $q_{L}^{W}=\omega q_{L}^{S S A}+(1-\omega) q_{L}^{R o W}$

Where $\omega$ is the share of SSA in global cropland cover. Equations (6) and (8) allow us to deduce the change in regional land use, once we know the change in world prices resulting from the technological progress in the RoW region:

(20) $q_{L}^{W}=\omega\left(v_{L}^{S S A} / \theta_{L}^{S S A}\right) p_{O}+(1-\omega)\left(v_{L}^{R o W} / \theta_{L}^{R O W}\right)\left(p_{O}+a^{R o W}\right)$

Substituting in the equilibrium solution for world prices, as a function of the TFP change we have:

(21) $q_{L}^{W}=-\omega\left(v_{L}^{S S A} / \theta_{L}^{S S A}\right) \gamma_{O}^{R o W} a^{R o W}+(1-\omega)\left(v_{L}^{R o W} / \theta_{L}^{R O W}\right)\left(1-\gamma_{O}^{R o W}\right) a^{R o W}$

where: $\gamma_{O}^{R o W}=\left(\varepsilon_{S}^{R o W}+1\right) /\left[\left\{\left(\varepsilon_{D}^{W}+\alpha \varepsilon_{S}^{S S A}\right) /(1-\alpha)\right\}+\varepsilon_{S}^{R o W}\right]$

Clearly land use in the SSA region will fall, since world prices are falling, but land use in the RoW region is ambiguous. If $\gamma_{O}^{\text {RoW }}<1$, then the second term in (21) will be positive and land use will rise in RoW. But this is the same condition for the excess demand elasticity facing producers in RoW to be inelastic: $\left\{\left(\varepsilon_{D}^{W}+\alpha \varepsilon_{S}^{S S A}\right) /(1-\alpha)\right\}<1$, from the single region analysis above, this is also the condition under which land rents rise, and land use expands in the face of TFP improvements. 
Since global land use is just the weighted summation of land use in SSA and RoW, in the case where the excess demand elasticity facing producers in RoW is elastic, land use unambiguously falls. However, when it is inelastic, the answer is not as clear cut. However, under the simplifying assumption that land supply response to commodity price changes is the same in both regions, i.e., $\left(v_{L}^{S S A} / \theta_{L}^{S S A}\right)=\left(v_{L}^{\text {RoW }} / \theta_{L}^{\text {RoW }}\right)$ equation (21) simplifies to the following:

(22) $q_{L}^{W}=-\omega\left(v_{L} / \theta_{L}\right) \gamma_{O}^{R o W} a^{R o W}+\left(v_{L} / \theta_{L}\right)\left(1-\gamma_{O}^{R o W}\right) a^{R o W}-\omega\left(v_{L} / \theta_{L}\right) a^{R o W}+\omega\left(v_{L} / \theta_{L}\right) \gamma_{O}^{R o W} a^{R o W}$ Canceling the first and last terms on the RHS of (22) gives:

$$
q_{L}^{W}=\left(v_{L} / \theta_{L}\right)\left(1-\gamma_{O}^{R o W}\right) a^{R o W}-\omega\left(v_{L} / \theta_{L}\right) a^{R o W}=\left(v_{L} / \theta_{L}\right)\left(1-\gamma_{O}^{R o W}-\omega\right) a^{R o W}
$$

This term is most likely to be positive when the region experiencing TFP growth is large (so $\omega \rightarrow 0)$ and when excess demand is very elastic.

If, in addition, the intensive margins of supply response are the same in both regions, then the elasticity of world prices with respect to TFP simplifies as follows:

$\left.\gamma_{O}^{\text {RoW }}=\left(\varepsilon_{S}+1\right) /\left[\left\{\left(\varepsilon_{D}^{W}+\alpha \varepsilon_{S}\right) /(1-\alpha)\right\}+\varepsilon_{S}\right]=(1-\alpha)\left(\varepsilon_{S}+1\right) /\left(\varepsilon_{D}^{W}+\varepsilon_{S}\right)\right]$

Therefore, global land use will rise, if and only if the following condition is satisfied:

$1>\gamma_{O}^{R o W}+\omega=(1-\alpha)\left(\varepsilon_{S}+1\right) /\left(\varepsilon_{D}^{W}+\varepsilon_{S}\right)+\omega$

This can be rewritten as follows:

(24) $(1-\omega) /(1-\alpha)>\left(\varepsilon_{S}+1\right) /\left(\varepsilon_{D}^{W}+\varepsilon_{S}\right)$

The LHS of this expression is the ratio of the RoW's share in global land use to its share in global production. But is just the ratio of inverse yields in RoW to inverse yields in the world, which is also equal to the ration of yields in the world to yields in RoW. So what equation (24) tells us is that, if yields in RoW are relatively high (relative to SSA), then it is unlikely that global land use will rise. Conversely, if yields in the innovating region (RoW) were relatively low, it would be 
possible that TFP growth in that region could cause global land use to rise, as production in the low-yielding region displaces that in the high yielding region. Of course, in the case of SSA, we know that crop yields are low, therefore virtually assuring at innovation in RoW will reduce global land use when markets are fully integrated.

Adding Conservation Measures: We treat the conservation programs as a backward shift in the land supply function in equation (6) in Box A1: $\Delta_{L}>0$, we can follow the same steps above and derive the new quantity supplied and price equilibrium conditions for the single region model as follows:

(25) $q_{O}=\varepsilon_{S} p_{O}+\left(\varepsilon_{S}+1\right) a-\Delta_{L}$

(26) $p_{O}=\left[\Delta_{D}+\Delta_{L}-\left(\varepsilon_{S}+1\right) a\right] /\left(\varepsilon_{S}+\varepsilon_{D}\right)$

The conservation measure operates as a backward shift in the supply curve and, in terms of equilibrium price, it operates in the same way as a shift in commodity demand. In the case of a wealthy economy (e.g., the Northern Europe), with stable population growth and food-satiated consumers, demand growth may be minimal. In this case, prices can remain stable as long as the conservation measures do not overwhelm TFP growth, i.e., $\Delta_{L} \leq\left(\varepsilon_{S}+1\right) a o$. In the context of the two region model, we have the following equilibrium condition for world price (equation (11) in the main text):

$$
p_{O}=\left[(1-\alpha) \Delta_{L}^{R o W}-(1-\alpha)\left(\varepsilon_{S}^{R o W}+1\right) a^{R o W}\right] /\left[\varepsilon_{D}^{W}+\varepsilon_{S}^{W}\right]
$$

\section{B. Quantitative Trade Model}

The Simplified International Model of Prices Land use and the Environment (SIMPLE) model is a multidimensional extension of the theoretical model in Box A1. Rather than two regions, there are an arbitrarily large number of geographic regions in SIMPLE (15 in the current implementation - see Table A1). In addition, nonland factor supplies are not perfectly elastic, reflecting the fact 
that other factors of production (most notably labor) are inelastically supplied to agriculture in many parts of the world. Another key extension is the incorporation of the equation determining current TFP growth as a function of past investments in agricultural R\&D (main text, equation (9)). Finally, in the segmented markets version of SIMPLE, there is imperfect price transmission from global markets into the domestic economy. While this quantitative trade model is expressed in linearized form, it is solved using nonlinear methods that capitalize on update formulae based on the underlying cost functions. Thus it can be thought of as a one-shot, comparative static model that takes the global economy from one equilibrium (e.g., 2006) to a future equilibrium (e.g., 2050). It is validated based on its ability to predict historical outcomes (e.g., 1961) for key variables, based on a backcasting exercise (see below).

In our quantitative trade model (Figure A1), per capita consumer demands are also disaggregated into three food types: crops, livestock and processed foods. These demands are loglinear functions of price and income, with respective food demand elasticities varying as a function of per capita income in each region. Based on international cross-section estimates by Muhammad et al. (2011), the absolute values of the income and price elasticities for all food types fall as incomes grow. Regional food demand is obtained by multiplying per capita demand by regional population. Since livestock and processed foods are valued-added products, these are produced within the consuming region using crop and non-crop inputs and therefore have region-specific prices. A substantial share of crop demands in the model is derived demands, obtained from the consumer demands for value-added food products. This is important, since technological change and factor substitution in the livestock and processed food industries can lead to varying intensities of crop use in these food products. The global demand for crops is the summation of final demands 
and derived demands summed over all regions. World demand for crop feed stocks in biofuels is exogenously specified and serves as an addition to global crop demand.

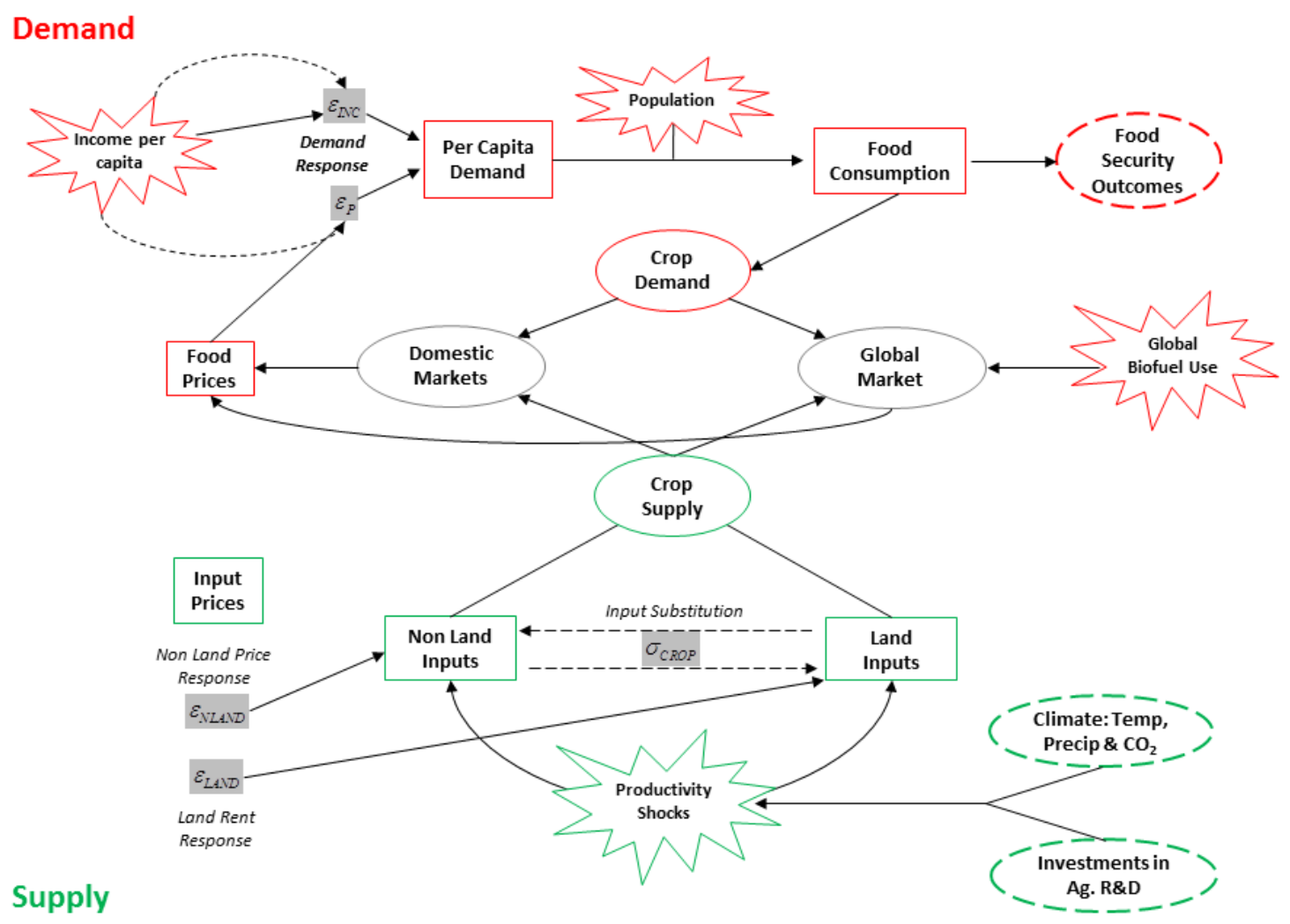

Figure A1. Diagram of the SIMPLE Model.

The bottom panel (green) refers to regional crop production for the aggregate crop commodity. The upper panel (red) refers to regional crop demand. The disposition of crops includes direct consumption, feedstuff use and food processing, as well as biofuels. Under market segmentation, consumers and producers interact in the domestic and international crop markets. Under integrated markets there is just a single global market and one price in all regions. The following are key parameters for each region: $\varepsilon_{I N C}$ and $\varepsilon_{P}$ are the price and income elasticities for each of the four consumption commodities. These vary with per capita income and therefore evolve over time. The elasticity of substitution between land and nonland inputs, $\sigma_{\text {CROP }}$, and determines the potential for endogenous intensification of production. The supply elasticities of land and nonland inputs to the crops sector, $\varepsilon_{L A N D},\left(v_{L}\right.$ in the theoretical model), $\varepsilon_{N L A N D}$ and are also region-specific. 
Global crop production in the model is specified for each of the 15 geographic regions as a CES function of land and non-land inputs, each with different yields and potentially differing rates of technological progress across regions. Cropland supply elasticities, which vary by region, are based on the adjusted estimates of Gurgel, Reilly, and Paltsev (2007) and Ahmed, Hertel, and Lubowski (2008). Non-land factor supplies to agriculture are also less than perfectly elastic supply, but are more price responsive than land supply, based on the estimates offered by OECD (OECD 2001). In the standard version of the SIMPLE model, equilibrium is attained in the crop markets when supply equals demand where the equilibrating variable is the global price of crops. In the segmented markets version of SIMPLE model there is a finite elasticity of substitution between crop commodities in the domestic and international markets and similarly a CET function determining supply to the global market.

We then compute the malnutrition headcount as our measure of food insecurity. The index measures the prevalence of undernourishment by reporting the fraction of population whose daily dietary energy intake is below the minimum requirement (FAO 2012). In the literature, it is common to focus on changes in malnutrition incidence (Alexandratos and Bruinsma 2012; Alexandratos 2009). Mathematically, the malnutrition index is equivalent to the poverty index measure proposed by Foster, Greer and Thorbecke (1984). Given this, we can use the concept of poverty-growth elasticity to link this measure to the average per capita dietary energy intake. Widely used in the poverty literature, the growth elasticity measures the percent changes in the indices of poverty given a one percent change in average per capita income (Bourguignon 2003; Lopez and Serven 2006). To apply this concept in the case of dietary energy, we assume that the distribution of per capita dietary energy consumption is lognormal. This is consistent with the traditional assumption used by FAO regarding the distribution of dietary energy intake within a 
country (Neiken 2003). The following equation is used to calculate the growth elasticity for the malnutrition index $\left(\varepsilon_{M I}\right)$.This characterizes the percent change in this index in the wake of a one percent rise in average dietary energy consumption (DEC):

(22) $\varepsilon_{M I}=-\frac{1}{\Omega} \frac{\tau}{\pi}\left[\frac{\ln (w / y)}{\Omega}+\frac{\Omega}{2}\right]$

In this equation, $w$ is the minimum daily energy requirement (MDER), $y$ is the average per capita DEC, and $\Omega$ is the standard deviation of the DEC distribution. The operators $\tau$ and $\pi$ denote the standard normal probability density and cumulative distribution functions, respectively. To compute the updated malnutrition headcount, we simply multiply the malnutrition index by the population headcount. To implement the model, we rely on the food security data published by FAO (2012; 2010).

\section{Additional Results}

Figure A2 reports the extent of global market penetration in regional crop consumption and production. These shares play a key role in the segmented markets model. A low rate international market participation will translate into limited international price transmission into the domestic market. This is clearly the case for the SSA region for which both demand and supply shares from/to international markets are quite low.

Table A1 reports the exogenous drivers used in our historical validation of the SIMPLE model for the 1961-2006 period. These include: population, income per capita, TFP for the crops, livestock and processed foods sectors, factor supply shifts for three regions: rural labor supply in Africa and irrigation supplies in South and Southeast Asia, all of which grew at extraordinary rates over this period due to exogenous factors (e.g., the green revolution in Asia). 
Table A1. Average Annual Growth Rates for Historical Validation: 1961-2006

\begin{tabular}{|c|c|c|c|c|c|c|}
\hline \multirow[b]{2}{*}{ Region } & \multirow[b]{2}{*}{ Population } & \multirow{2}{*}{$\begin{array}{l}\text { Per Capita } \\
\text { Income }\end{array}$} & \multicolumn{3}{|c|}{ Total Factor Productivity (TFP) } & \multirow{2}{*}{$\begin{array}{l}\text { Other } \\
\text { Drivers }\end{array}$} \\
\hline & & & Crops & Livestock & $\begin{array}{l}\text { Processed } \\
\text { Foods }\end{array}$ & \\
\hline Eastern Europe & 0.46 & -1.72 & 0.40 & 0.66 & \multirow{15}{*}{$\begin{array}{c}1.09 \\
\text { for all } \\
\text { regions }\end{array}$} & \\
\hline North Africa & 2.61 & 1.33 & 3.13 & 0.18 & & \\
\hline Sub Saharan Africa & 2.77 & -0.42 & 0.84 & 0.43 & & 3.5 \\
\hline South America & 2.06 & 1.38 & 2.53 & 0.96 & & \\
\hline Australia+New Zealand & 1.46 & 1.94 & 1.99 & 1.14 & & \\
\hline European Union & 0.43 & 2.46 & 2.28 & 1.14 & & \\
\hline South Asia & 2.20 & 2.33 & 1.51 & 0.59 & & 3.3 \\
\hline C. America + Caribbean & 2.29 & 1.69 & 1.20 & 0.96 & & \\
\hline South Africa & 2.34 & 0.36 & 1.90 & 0.43 & & \\
\hline South East Asia & 2.25 & 3.15 & 2.13 & 1.05 & & 3.3 \\
\hline Canada+United States & 1.03 & 2.19 & 2.52 & 1.14 & & \\
\hline China & 1.62 & 6.78 & 3.23 & 1.05 & & \\
\hline Middle East & 2.27 & 2.37 & 2.34 & 0.18 & & \\
\hline Japan+Korea & 0.87 & 3.42 & 3.47 & 1.14 & & \\
\hline Central Asia & 2.43 & -2.49 & 0.40 & 0.66 & & \\
\hline
\end{tabular}

The growth rates are calculated from these sources: Population and per capita incomes from World Development Indicators (2019); crop TFP from Fuglie (2012), livestock TFP from Ludena et al (2007) and processed foods TFP from Griffith, Redding and Reenen (2004). Other drivers are non-land input supplies in Sub-Saharan Africa (based on labor force growth rate) and South \& Southeast Asia (based on the growth in area equipped for irrigation). These other drivers are subsumed in the productivity component of the historical decomposition in Figure 6 of the main text.

Figure 6 in the main text compares the actual and model-predicted changes in global crop production and composite world price for crops over this historical period. Figure A3 below provides this same comparison for two other key observables: crop yields and cropland area. These figures demonstrate that SIMPLE does a good job capturing global changes in the agricultural sector over a 45 year period. However, capturing regional changes in such a simple model is more challenging. Figure A4 shows that crop growth in Latin America, in particular, was much more rapid than predicted by the model over this historical period. There are many potential reasons for this, including the opening up of vast areas of farmland in Brazil. 


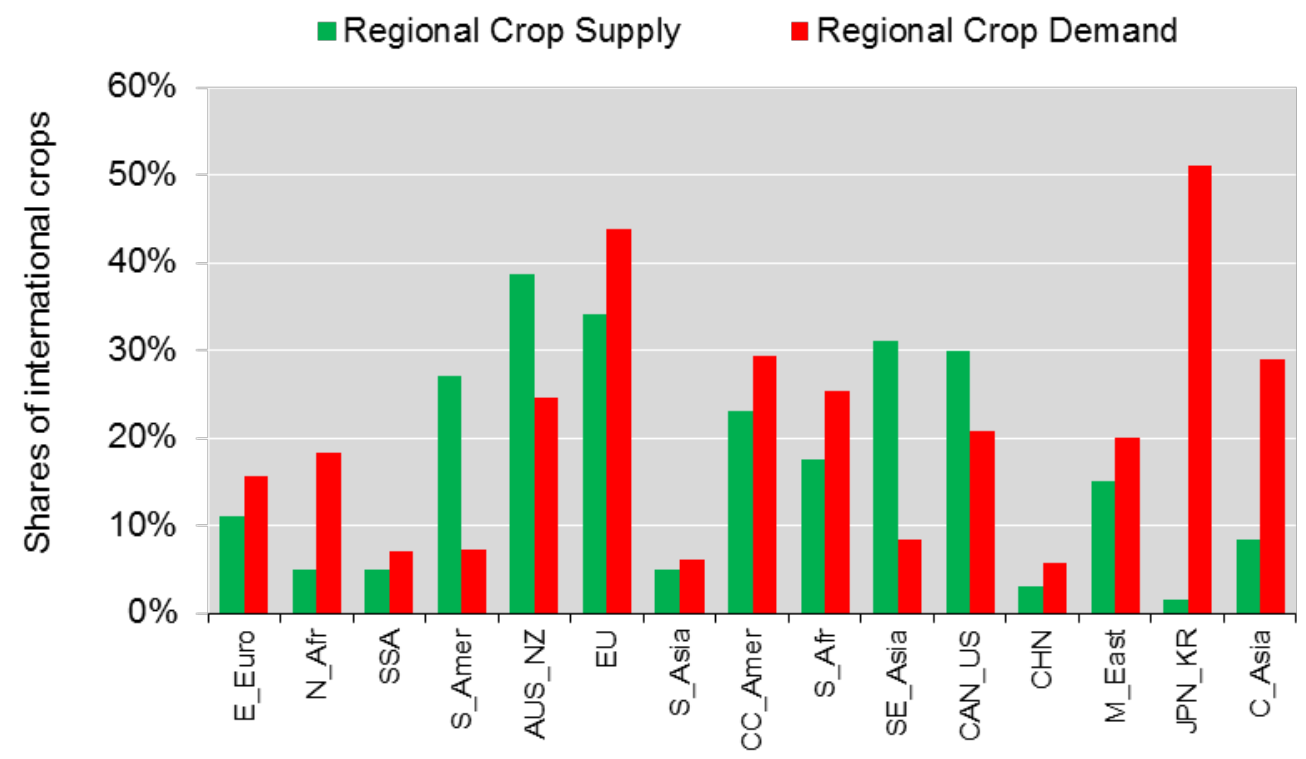

Figure A2. Metrics for Trade Integration in Agricultural Markets.

The red columns give the share of imports in the regional demand expenditures for crop commodities. The green columns give the share of exports in crop production revenues. Data are for 2006 (Source: FAO). Complete names of each regions are as follows (left to right): Eastern Europe, North Africa, Sub Saharan Africa, South America, Australia+New Zealand, European Union, South Asia, Central America + Caribbean, South Africa, South East Asia, Canada+United States China, Middle East, Japan+Korea, Central Asia, respectively.

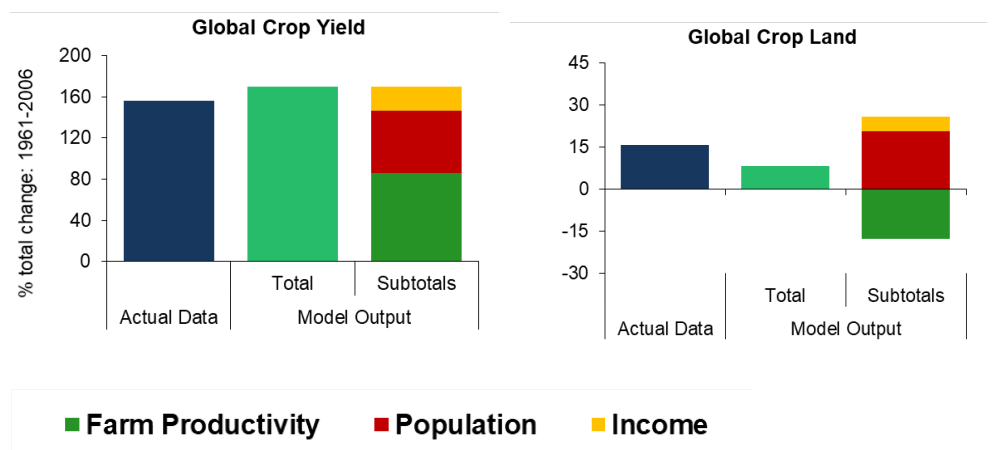

Figure A3. Historical Validation and Decomposition of Key Drivers of Global Crop Production and Prices. Historical data on crop yield and crop land from FAOSTAT (2019). (See also Figure 6 in the main text.) Other drivers are non-land input supplies in Sub-Saharan Africa (based on labor force growth rate) and South \& Southeast Asia (based on the growth in area equipped for irrigation) are subsumed in the productivity component of the historical decomposition in Figure 6 of the main text. 


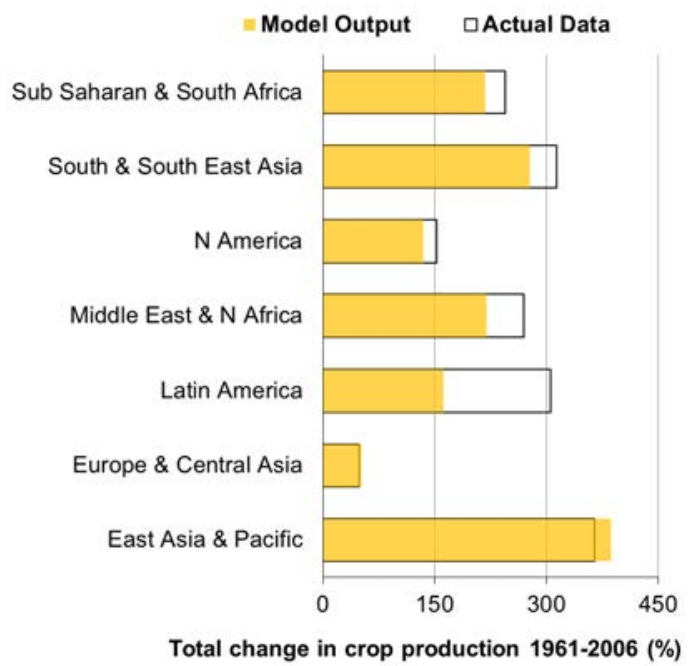

Figure A4. Historical Validation and Decomposition of Growth in Regional Crop Production Over 1961-2006. Historical data on crop yield and crop land from FAO (2019). (See also Figure 6 in the main text.) Note the shortfall in model predictions for crop expansion in Latin America. The drivers of crop production in SIMPLE are just population, income, biofuels and Total Factor Productivity (TFP). Other factors, such as the opening up of vast areas of Brazil to agriculture, are not considered.

Table A2 reports the exogenous drivers of SIMPLE going forward to mid-century, along with their sources. Macro-economic trends are taken from the 'business as usual' Shared Socioeconomic Pathways scenario (SSP2). Productivity growth rates are based on expert projections from the literature (see legend for Table A2). 
Table A2. Key Average Annual Growth Rates for Future Projections : 2006-2050

\begin{tabular}{|c|c|c|c|c|c|c|}
\hline \multirow{3}{*}{ Region } & \multirow{3}{*}{ Pop } & \multirow{3}{*}{ Inc } & \multicolumn{4}{|c|}{ Total Factor Productivity } \\
\hline & & & \multicolumn{2}{|c|}{ Crops } & \multirow[b]{2}{*}{ Lstock } & \multirow[b]{2}{*}{$\begin{array}{l}\text { Proc } \\
\text { Foods }\end{array}$} \\
\hline & & & $\begin{array}{l}\text { Low } \\
\text { Spill }\end{array}$ & $\begin{array}{l}\text { High } \\
\text { Spill }\end{array}$ & & \\
\hline Eastern Europe & -0.36 & 3.14 & 0.44 & 0.44 & 1.31 & \\
\hline North Africa & 0.89 & 3.16 & 1.05 & 1.88 & -0.28 & \\
\hline Sub Saharan & 2.18 & 4.08 & & & & \\
\hline Africa & & & 0.45 & 1.00 & 0.47 & \\
\hline South America & 0.68 & 2.49 & 3.32 & 5.36 & 4.89 & \\
\hline Australia+New & 0.71 & 1.29 & & & & \\
\hline Zealand & & & 1.60 & 1.60 & 0.46 & \\
\hline European Union & -0.01 & 1.26 & 1.97 & 1.97 & 0.46 & \\
\hline South Asia & 0.84 & 5.06 & 2.08 & 3.50 & 2.52 & \\
\hline $\begin{array}{l}\text { Central } \\
\text { America + }\end{array}$ & 0.87 & 2.33 & & & & 1.09 \\
\hline Caribbean & & & 2.88 & 4.56 & 4.89 & \\
\hline South Africa & 0.36 & 3.16 & 0.67 & 1.32 & 0.47 & \\
\hline South East Asia & 0.68 & 3.87 & 1.18 & 2.06 & 4.12 & \\
\hline Canada+United & 0.56 & 1.12 & & & & \\
\hline States & & & 1.78 & 1.78 & 0.46 & \\
\hline China & -0.16 & 4.78 & 3.04 & 4.88 & 4.12 & \\
\hline Middle East & 1.23 & 1.68 & 1.04 & 1.86 & -0.28 & \\
\hline Japan+Korea & -0.40 & 1.74 & 1.87 & 1.87 & 0.46 & \\
\hline Central Asia & 1.04 & 4.00 & 0.63 & 0.63 & 1.31 & \\
\hline
\end{tabular}

Sources: The following growth rates are calculated from these sources: Population and per capita incomes from Shared Socioeconomic Pathway (SSP) Projections Database v0.5 (Kriegler et al. 2012, O'Neill et al. 2014) for population and per capita income growth rates; Total Factor Productivity Growth for Crops from authors' calculations, for Livestock from Ludena et al (2007) and for Processed Foods from Griffith et al (2004)

One of the key assumptions in our future projections is that the historical relationship between knowledge capital and TFP growth will hold in the future (i.e., the elasticities in equation (12) are unchanging). While this may be reasonable in many cases, there are two instances where we believe some robustness checks are in order. Figure A5 reports the results of these sensitivity analyses in these two cases. The first pertains to Asia - particularly China -- where extremely high rates of current agricultural R\&D investments are leading to rapid growth in knowledge capital and there is some concern about whether these investments will be as productive as in the past. The left hand panel of this figure shows the consumer prices changes in SSA under the assumption 
that $\delta_{O}$ is just half as large for Asia as in the historical simulation (0.105 instead of 0.210). In this case, the impact of virtual technology trade is a smaller driver of crop prices in SSA, although some of this is picked up by other factors so that the total difference in prices under the baseline case is modest $(-2.4 \%$ vs. $-7.6 \%)$.

The second robustness check pertains to the productivity of knowledge capital in the SSA region. Historically, $\delta_{O}$ for SSA was just half as large as for the developed regions. This makes it difficult for R\&D investments to make a big impact on future productivity. With a general improvement in macroeconomic conditions coupled with recent increases infrastructure investment (especially from China) the environment may be more conducive for technology dissemination in this region, which could raise the estimated marginal productivity of investments in R\&D. In the sensitivity analysis presented in the right-hand panel of Figure A5, we report the impacts of the different types of technology trade on crop prices in SSA for the case where this elasticity for SSA is doubled so that it reaches the values estimated for the more developed regions (0.26 instead of 0.13). This more than doubles the contribution of 'Own Tech' to crop price reduction in SSA, and it leads to a further 5\% reduction in overall prices in the baseline $(-12.4 \%$ vs. -7.6\%) under segmented markets. However, unlike the case of Asia - a large player in global markets - doubling the knowledge capital elasticity for SSA has little impact on crop prices in the region under fully integrated markets. 


\section{Future Drivers of Consumers' Crop Price in SSA: 2006-2050 \\ Smaller Own Tech in Asia \\ Greater Own Tech in SSA}

100

100

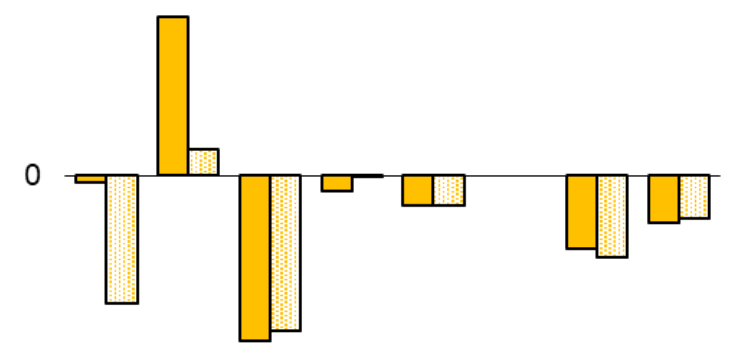

0

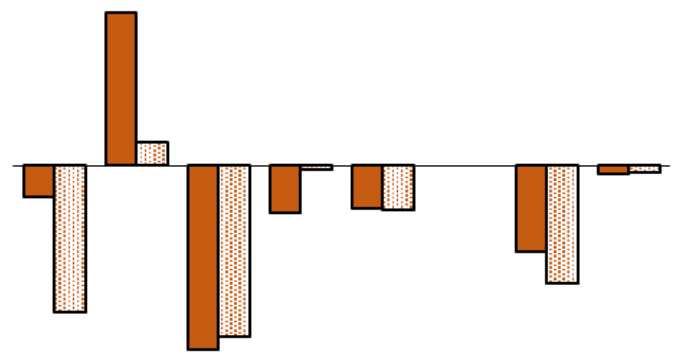

$-100$

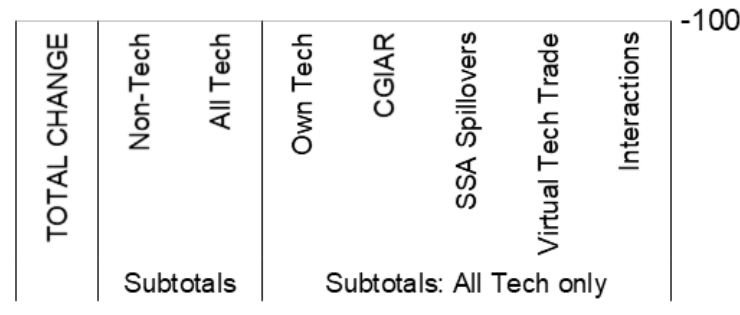

口Segmented

ㅁIntegrated

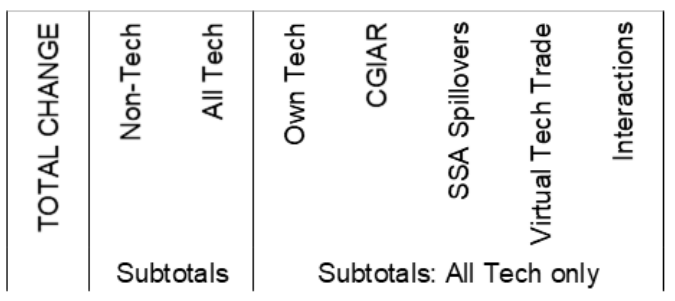

口Segmented $\quad$ Integrated

Figure A5. Robustness analysis with respect to the own-knowledge capital elasticities in equation (9). The left-hand panel reports the case where the elasticities in Asia is cut in half for the future projections. The right-hand panel reports results whereby the own-elasticity is doubled for the SSA region.

\section{Appendix References}

Ahmed, S.A., Thomas W. Hertel, and Ruben Lubowski. 2008. "Calibration of a Land Cover Supply Function Using Transition Probabilities.” GTAP Research Memorandum 14. West Lafayette, Indiana, USA: Center for Global Trade Analysis, Department of Agricultural Economics, Purdue University.

Alexandratos, Nikos. 2009.World Food and Agriculture to 2030/2050. Highlights and Views from Mid-2009. Paper for the Expert Meeting on "How to Feed the World in 2050," FAO, Rome, 24-26 June 2009 (revised 25 July 2009).

Alexandratos, Nikos, and Jelle Bruinsma. 2012. World Agricultural Towards 2030/2050: The 2012 Revision. ESA Working Paper No. 12-03, FAO, Rome.

Bourguignon, Francois. 2003. “The Growth Elasticity of Poverty Reduction; Explaining Heterogeneity Across Countries and Time Periods.” In, Inequality and Growth: Theory and Policy Implications (eds., T.S. Eicher and S.J. Turnovsky). Cambridge, MA: MIT Press. Pp 3-26.

FAO. 2010. FAO Statistical Yearbook. Food and Agriculture Organization of the UnitedNations, Rome, Italy. 
FAO. 2012. FAO Food Security Statistics. (online). Available from URL: http://www.fao.org/economic/ess/en/ [accessed 12 June 2012].

FAO. 2019. FAOSTAT Statistical Database. Accessed 2019. http://faostat.fao.org/.

Foster, James, Joel Greer, and Erik Thorbecke. 1984. "A Class of Decomposable Poverty Measures.” Econometrica 52 (3): 761-66. https://doi.org/10.2307/1913475.

Fuglie, Keith. 2012. "Productivity Growth and Technology Capital in the Global Agricultural Economy.” In Productivity Growth In Agriculture: An International Perspective, edited by Keith Fuglie, Sun Ling Wang, and V Eldon Ball, 335-68. Cambridge, MA, USA: CAB International.

Gohin, Alex, and Thomas W. Hertel. 2003. "A Note on the CES Functional Form and Its Use in the GTAP Model.” GTAP Research Memorandum No. 2, Global Trade Analysis Project (GTAP), Purdue University, West Lafayette, Indiana, USA.

Griffith, R., Redding, S., \& Reenen, J. V. (2004). "Mapping the Two Faces of R\&D: Productivity Growth in a Panel of OECD Industries”. Review of Economics and Statistics 86 (4): 883- 895. http://doi.org/10.1162/0034653043125194

Gurgel, Angelo, John M. Reilly, and Sergey Paltsev. 2007. "Potential Land Use Implications of a Global Biofuels Industry.” Journal of Agricultural \& Food Industrial Organization 5 (2): $1-36$.

Kriegler, E., O’Neill, B. C., Hallegatte, S., Kram, T., Lempert, R. J., Moss, R. H., \& Wilbanks, T. 2012. "The Need For and Use of Socio-economic Scenarios for Climate Change Analysis: A New Approach Based on Shared Socio-economic Pathways.” Global Environmental Change 22 (4): 807-822. http://doi.org/10.1016/j.gloenvcha.2012.05.005

Lopez, Humberto, and Luis Serven. 2006. "A Normal Relationship? Poverty, Growth, and Inequality.” Policy Research Working Papers, World Bank, Washington, DC, January.

Ludena, C.E., Hertel, T.W., Preckel, P.V., Foster, K. and Nin, A. (2007). "Productivity Growth and Convergence in Crop, Ruminant, and Nonruminant Production: Measurement and Forecasts.” Agricultural Economics 37(1): 1-17

Muhammad, Andrew, James L. Seale Jr., Birgit Meade, and Anita Regmi. 2011. "International Evidence on Food Consumption Patterns: An Update Using 2005 International Comparison Program Data.” Technical Bulletin TB-1929. Washington, D.C., USA: Economic Research Service, US Department of Agriculture. http://www.ers.usda.gov/Publications/TB1929/.

Neiken, L. (2003). FAO Methodology for Estimating the Prevalence of Undernourishment. FAO, Rome, Italy.

OECD. 2001. "Market Effects of Crop Support Measures.” Paris, France: OECD.

O'Neill, Brian, et al. 2017. "The Roads Ahead: Narratives for Shared Socioeconomic Pathways Describing World Futures in the $21^{\text {st }}$ Century.” Global Environmental Change 42 (January): 169-180.

World Development Indicators. 2019. (online datbase). World Bank. https://databank.worldbank.org/source/world-development-indicators 